畨

\title{
POLÍTICAS DE CONSERVAÇÃO AMBIENTAL E DE IDENTIDADE ÉTNICA NO SÉCULO XXI: PERSPECTIVAS DA ECOLOGIA POLÍTICA, DA HISTÓRIA AMBIENTAL E DA ONTOLOGIA RELACIONAL
}

\section{- SCOTT WILLIAM HOEFLE ${ }^{1}$}

1 Professor Titular, Programa de Pós-graduação em Geografia, Universidade Federal do Rio de Janeiro. E-mail para contato: scotthoefle@acd.ufrj.br

Recebido em:10/07/2020

Aprovado em: 22/01/2021

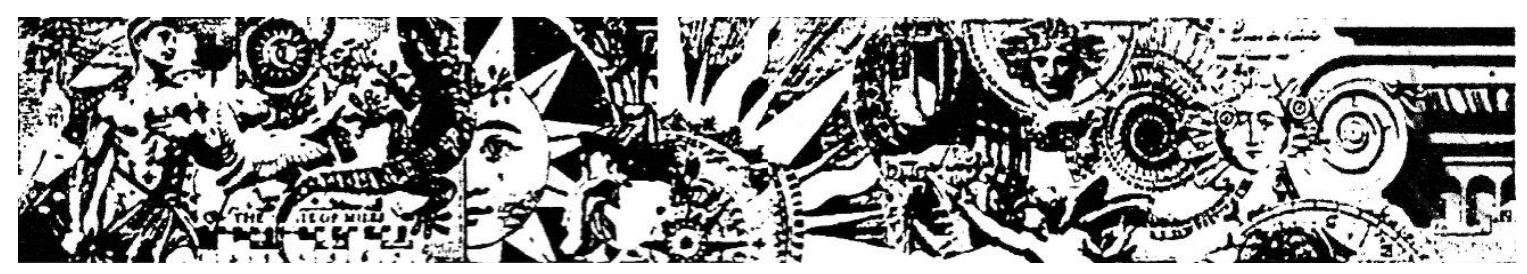

Resumo: Num contexto global de polarização populista sobre questões ambientais e culturais, uma combinação das abordagens da Ecologia Política, da História Ambiental e da Ontologia Relacional é utilizada para explorar uma terceira via de transformação socioambiental situada entre os extremos da conservação biocêntrica e do desenvolvimento predatório: a conservação socioecológica. A Ecologia Política e a História Ambiental do século XXI mostram como a conservação biocêntica somente zela pela preservação natural e o desenvolvimento predatório favorece apenas alguns interesses econômicos específicos, de forma que ambos promovem ampla exclusão social. Em reação à injustiça ambiental e social, populações rurais históricas buscam formas de resistir ao cerceamento ambiental resultante da conservação biocêntrica global. A perspectiva relacional, por sua vez, permite entender melhor a complexidade e as contradições das estratégias de permanência no lugar que no país são baseadas em reservas de desenvolvimento sustentável e de territórios étnicos. A visão híbrida mesclando as três abordagens é ilustrada em dois casos empíricos, um na Amazônia no qual existe conflito por território entre indígenas e ribeirinhos e outro no Pantanal envolvendo cooperação entre os dois grupos étnicos. 
Palavras-Chave: Ecologia Política Crítica, História Ambiental Radical, Ontologia Relacional, conservação socioecológica, complexidade cultural híbrida, Amazônia, Pantanal.

ENVIRONMENTAL CONSERVATION AND ETHNIC IDENTITY POLICIES IN THE 21ST CENTURY: POLITICAL ECOLOGY, ENVIRONMENTAL HISTORY AND RELATIONAL ONTOLOGY PERSPECTIVES

\begin{abstract}
AT A TIME OF GLOBAL POPULIST POLITICAL POLARIZATION CONCERNING ENVIRONMENTAL AND CULTURAL ISSUES, A COMBINATION OF POLITICAL ECOLOGY, ENVIRONMENTAL HISTORY AND RELATIONAL ONTOLOGY IS USED TO EXPLORE A THIRD KIND OF CONSERVATION SITUATED BETWEEN THE EXTREME OF BIOCENTRIC CONSERVATION AND PREDATORY DEVELOPMENT: SOCIO-ECOLOGICAL CONSERVATION. TWENTY-FIRST CENTURY POLITICAL ECOLOGY AND ENVIRONMENTAL HISTORY SHOW HOW BIO-CENTRIC CONSERVATION IS ONLY INTERESTED IN NATURAL PRESERVATION AND PREDATORY DEVELOPMENT FAVORS CERTAIN ECONOMIC INTERESTS SO THAT BOTH PROMOTE WIDESPREAD SOCIAL EXCLUSION. IN REACTION TO ENVIRONMENTAL AND SOCIAL INJUSTICE, HISTORIC RURAL POPULATIONS SEARCH FOR WAYS TO RESIST NATURE ENCLOSURES RESULTING FROM GLOBAL BIO-CENTRIC CONSERVATION. A RELATIONAL PERSPECTIVE PERMITS A BETTER UNDERSTANDING THE COMPLEXITY AND CONTRADICTIONS INHERENT IN STRATEGIES FOR REMAINING IN PLACE, WHICH IN BRAZIL ARE BASED ON SUSTAINABLE DEVELOPMENT RESERVES AND ETHNIC TERRITORIES. A HYBRID BLENDING OF THE THREE THEORETICAL APPROACHES IS ILLUSTRATED IN TWO EMPIRICAL CASES, ONE IN THE AMAZON IN WHICH TERRITORIAL CONFLICT EXISTS BETWEEN INDIGENES AND RIVERINE PEASANTS AND ANOTHER IN THE PANTANAL INVOLVING COOPERATION BETWEEN THESE TWO ETHNIC GROUPS.

KEYWORDS: CRITICAL POLITICAL ECOLOGY; RADICAL ENVIRONMENTAL HISTORY; RELATIONAL ONTOLOGY; SOCIO-ECOLOGICAL CONSERVATION; HYBRID CULTURAL COMPLEXITY; AMAZON; PANTANAL.
\end{abstract}

POLITICAS DE CONSERVACIÓN AMBIENTAL E IDENTIDAD ÉTNICA EN EL SIGLO XXI: PERSPECTIVAS DE ECOLOGÍA CRÍTICA, HISTORIA AMBIENTAL Y ONTOLOGÍA RELACIONAL

RESUMEN: EN UN CONTEXTO GLOBAL DE POLARIZACIÓN POPULISTA EN TEMAS AMBIENTALES Y CULTURALES, SE UTILIZA UNA COMBINACIÓN DE LOS ENFOQUES DE ECOLOGÍA POLÍTICA, HISTORIA AMBIENTAL Y ONTOLOGÍA RELACIONAL PARA EXPLORAR UNA TERCERA VÍA DE TRANSFORMACIÓN SOCIOAMBIENTAL UBICADA ENTRE LOS EXTREMOS DE LA CONSERVACIÓN BIOCÉNTRICA Y EL DESARROLLO DEPREDADOR: LA CONSERVACIÓN SOCIOECOLÓGICA. LA ECOLOGÍA POLÍTICA Y LA HISTORIA AMBIENTAL DEL SIGLO XXI MUESTRAN CÓMO LA CONSERVACIÓN BIOCÉNTRICA SOLO SE OCUPA DE LA PRESERVACIÓN NATURAL Y EL DESARROLLO DEPREDADOR FAVORECE UNOS POCOS INTERESES ECONÓMICOS ESPECÍFICOS, POR LO QUE AMBOS PROMUEVEN UNA AMPLIA EXCLUSIÓN SOCIAL. EN RESPUESTA A LA INJUSTICIA AMBIENTAL Y SOCIAL, LAS POBLACIONES RURALES HISTÓRICAS ESTÁN BUSCANDO FORMAS DE RESISTIR LA INVASIÓN AMBIENTAL RESULTANTE DE LA CONSERVACIÓN BIOCÉNTRICA GLOBAL. LA PERSPECTIVA RELACIONAL, EN CAMBIO, NOS PERMITE COMPRENDER MEJOR LA COMPLEJIDAD Y CONTRADICCIONES DE LAS ESTRATEGIAS PARA LA PERMANENCIA EN EL PAÍS, QUE SE BASAN EN RESERVAS DE DESARROLLO SOSTENIBLE $Y$ 
TERRITORIOS ÉTNICOS. LA VISIÓN HÍBRIDA QUE MEZCLA LOS TRES ENFOQUES SE ILUSTRA EN DOS CASOS EMPÍRICOS EN EL PAÍS, UNO EN LA AMAZONÍA EN EL QUE EXISTE CONFLICTO TERRITORIAL ENTRE INDÍGENAS Y HABITANTES RIBEREÑOS Y EL OTRO EN EL PANTANAL QUE INVOLUCRA LA COOPERACIÓN ENTRE LAS DOS ETNIAS.

PALABRAS CLAVE: ECOLOGÍA POLÍTICA CRÍTICA, HISTORIA AMBIENTAL RADICAL, ONTOLOGÍA RELACIONAL, CONSERVACIÓN SOCIOECOLÓGICA, COMPLEJIDAD CULTURAL HÍBRIDA, AMAZONIA, PANTANAL.

\section{Apresentação}

Em ano recorte de incêndios descontrolados na Amazônia e no Pantanal, sinalizando o retorno ao velho desenvolvimento predatório no país, há urgência em implementar um modelo de conservação socioecológica com base teórica na Ecologia Política Crítica, na História Ambiental Radical e na Ontologia Relacional. Neste trabalho defendemos uma abordagem híbrida e pluralista à conservação ambiental e à identidade étnica visando superar as contradições presentes nas atuais políticas ambientais e de inclusão social no país.

São identificadas quatro estratégias usadas por indígenas e camponeses que buscam permanecer no lugar em unidades de conservação e territórios étnicos: 1) resistir à expulsão através da sabotagem, da desobediência pacífica e até da luta armada se for necessária, 2) mudar a mentalidade automática biocêntrica de gestores de unidades de conservação para uma visão socioecologica, 3) promover atividades sustentáveis, tais como a agroecologia, sistemas agroflorestrais agroflorestais e atividades madeireiras, não-madeireiras e turísticas de base comunitária e; 4) pleitear territórios étnicos não administrados por órgãos ambientais. As primeiras três estratégias geralmente se dão em sequência em unidades de conservação enquanto a quarta baseada em territórios étnicos pode ser adotada em reação às restrições impostas por órgãos ambientais.

\section{Abordagens teóricas sobre a relação da conservação sócio-ecológica com a identidade étnica}

Conceitos chave e métodos de abordagens teóricos do século XXI, sobre a resistência à injustiça ambiental e territorial praticada contra populações rurais históricas, são utilizadas para interpretar as contradições entre políticas ambientais e culturais apontadas em dois casos empíricos na Amazônia e no Pantanal. Com base nos conceitos de cerceamento e expropriação por natureza e de exploração urbano-rural da 
Ecologia Política e os conceitos de despossessão ambiental e refugiados da conservação da História Ambiental Radical, critica-se a conservação biocêntrica quando aplicada em parques nacionais de preservação integral. Os conceitos de sociedade-natureza híbrida, de re-grupamento de redes-ator e de conectividade da Ontologia Relacional, por sua vez, são mobilizados para mapear as estratégias utilizadas por populações históricas para superar a injustiça ambiental e social através de alianças e parcerias locais e translocais.

A Ecologia Política investiga relações desiguais de poder que marginaliza populações pobres e as expõem a maior risco de degradação ambiental, desastres naturais e mudanças climáticas globais. Céticos ao novo modelo de acumulação verde que oculta a real natureza destrutiva da acumulação capitalista, ecologistas políticos questionam soluções neo-liberais de mercados carbônicos, particularmente acordos REDD, que promovem lavagem verde da enorme quantidade de emissões dos países pós-industriais e industrializados na forma de compensações aplicadas em florestas sumidouros de carbono situadas em países do Sul Global. Com isso, nesses países ocorre um processo de cerceamento por unidades de conservação, a expropriação por natureza e até "guerras verdes" tramadas contra populações rurais pobres (BICALHO, HOEFLE, 2020; BUMPUS, LIVERMAN, 2011; BÜSCHER, FLETCHER, 2014, 2018; FORSYTHE 2003; HOEFLE, 2013; PEET et al., 2011). Como as unidades de conservação geralmente são criadas em áreas marginais, essencialmente, rurais, os pobres do campo são os atores que arcam com o ônus da política ambiental, processo que Kelly-Reif e Wing (2016) caracterizam como exploração urbana do rural.

Ao mesmo tempo em que a Ecologia Política Crítica e a História Ambiental Radical despontaram como as principais correntes críticas da conservação biocêntrica global, a abordagem da Ontologia Relcional foi construída a partir da guinada cultural nas ciências humanas no fim do século XX. Na Geografia os principais proponentes são Whatmore (2003), Cresswell (2013) e Marston et al. (2005) enquanto na Sociologia é Latour (1994, 2004, 2005, 2013) e na Antropologia são Descola (2013), Holbraad e Pedersen (2017), Rodseth (2015) e Viveiros de Castro (1998). A perspectiva relacional desenvolveu dois grandes eixos de inovação teórica sobre: 1) a superação do dualismo ocidental entre a sociedade/cultura humana e a natureza biológica e 2) a crítica ao conceito de escala e sua substituição com uma ontologia plana de relações sociopolíticas.

Latour (1994, 2004, 2013) e Descola (2013) são os maiores críticos da separação da sociedade humana e da natureza biológica, que eles alegam só existir na Ciência Ocidental Moderna. Há múltiplas culturas e naturezas e não uma única Natureza 
considerada ontologicamente independente, cujas verdades são desvendadas objetivamente apenas pela Ciência Ocidental. Em vez de ratear fenômenos por estudo aparte pelas ciências humanas e ciências biofísicas, que em função de diferenças epistemológicas e metodologias não se entendem, na visão relacional se propõe abolir esta separação e sua substituição pelo estudo holístico de redes de atores humanos e nãohumanos.

Para Latour (2013) a Natureza, bem como a Sociedade, não existem, porque são amalgamações incompletas que ocultam pelo menos quatorze modos de existência separados, cinco compartilhados com não-humanos e nove em coletivos humanos. Em obra anterior de 2004, Latour argumentou que a Ecologia Política é de suma importância para o planeta, mas somente se superar a visão ocidental da Natureza. Assim sendo, a Ecologia Política deveria ser muito mais do que a disputa desigual por recursos naturais.

Com rica documentação etnológica, Descola (2013), por sua vez, mostra que outros povos no mundo não se separam de uma Natureza independente, ameaçadora ou intocável. O surgimento desta visão bifurcada de mundo na Europa Ocidental é atribuído à colonização e domesticação da grande floresta européia pelos romanos; à revolução científica que promoveu um modelo mecânico da realidade; e à pintura de paisagens silvestres sem gente, que teve seu auge nos artistas românticos dos Estados Unidos no século XIX. Estes, por sua vez, foram instrumentais no surgimento do modelo norteamericano de conservação baseado em parques nacionais nas quais não é permitido morador humano. Para criticar este modelo, Descola cita um líder aborígine australiano, “O Parque Nacional de Nitmiluk não é "wilderness" (selva) ... é um artefato humano ... construído durante dezenas de mil anos, através de nossas cerimônias, por nossas relações de parentesco, pelo o uso do fogo e pela caça” (p.35-36, traduzido aqui).

Assim sendo, lançando mão da filosofia e da etnologia, o pensamento relacional chega às conclusões convergentes com a Ecologia Política e a História Ambiental, contrárias à conservação biocêntrica. Na verdade, a conservação biocêntrica e o desenvolvimento predatório se espelham na mesma visão secular da Ciência Moderna que separa o espaço humano do espaço natural (Figura 1). A conservação de alguns espaços "naturais remanescentes" autoriza a domesticação do espaço humano e seu desenvolvimento capitalista desenfreado (Figura 1).

A conservação socioecológica, por sua vez, desmonta as barreiras entre coletividades humanas e não-humanas e as regrupam em diferentes formas de articulação/co-habitação através dos quatorze modos de existência identificados por 
Latour (2013). Também retira o veto moderno contra incluir dimensões metafísicas na ontologia científica, tais como a metamorfose (divindades de transformação) e a religião (deuses da salvação e do fim do tempo) (Figura 2).

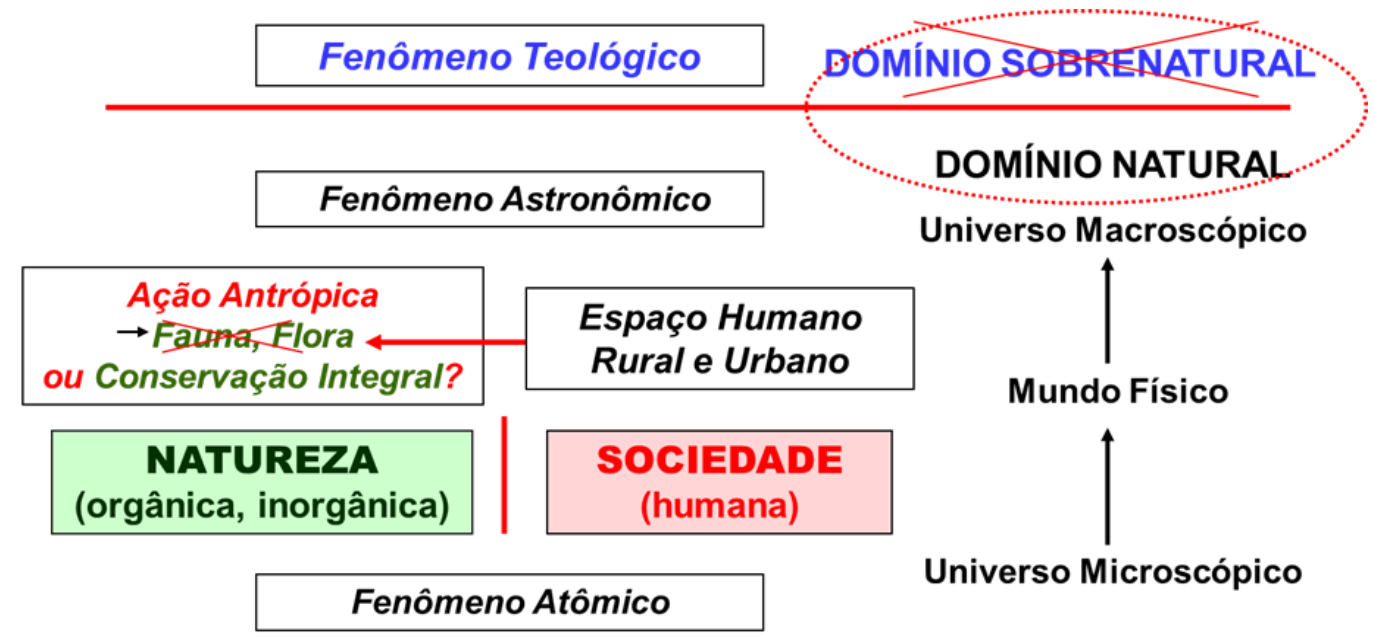

Figura 1 - Visão secular materialista da ciência mecanicista e reducionista.

Fonte: Elaborado pelo autor, 2020.

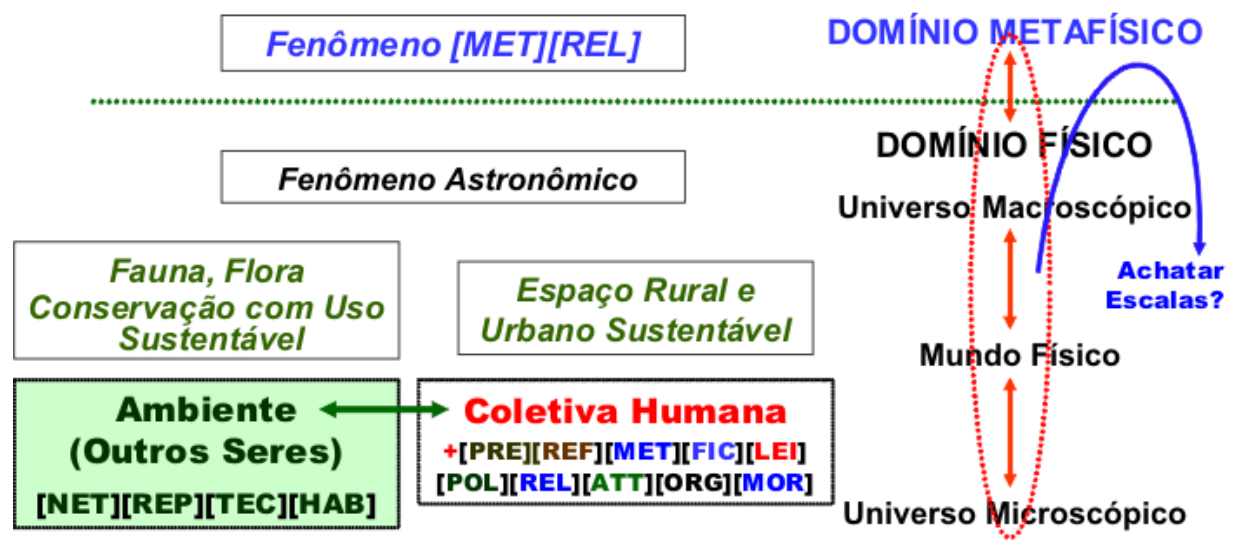

\section{Fenômeno Atômico}

\begin{tabular}{llll}
\multicolumn{3}{c}{ Modos Relacionais de Existência (segundo Latour, 2013) } \\
NET = rede & PRE = preposição & LEI = lei & ORG = organização \\
REP = reprodução & REF = referência & POL = política & MOR = moralidade \\
TEC = técnica & MET = metamorfose & REL = religião & \\
HAB = hábitos & FIC = ficção & ATT = apego
\end{tabular}

Figura 2 - Visão sócio-ecológica da ciência trans-disciplinar holística. Fonte: Elaborado pelo autor, 2020.

Já existe bem mais atrito entre a Ecologia Política e a Ontologia Relacional no eixo de investigação sobre relações sócio-políticas mobilizadas por atores rurais pobres para resistir o cerceamento por natureza. Ao propor a eliminação do conceito de escala na 
Geografia Humana, Martston et al. (2005) provocaram um debate intenso sobre como visualizar relações entre gente e lugar no mundo: de forma vertical em escalas hierárquicas do poder ou de forma plana e horizontal entre lugares distribuídos no espaço (para mais detalhes dirija-se a CRESSWELL, 2013; HOEFLE, 2006a; JONES III et al. 2007, 2011; LEITNER, MILLER, 2007)? No debate, a Ecologia Política ficou do lado da visão escalar, mesmo se através dos anos esta corrente absorveu métodos relacionais e a visão pluralista da natureza (LAVE, 2015; NEUMANN, 2015).

Contudo, a visão "terraplanista”, negando a existência de escala, é resultado de uma leitura limitada e superficial de Latour. Até mesmo Cresswell (2013) usa basicamente a obra preliminar de Latour de 1994 sobre redes científicas e uma leitura bastante seletiva da Reassemblying the Social de 2005. É verdade que na primeira parte do Reassemblying Latour condena o conceito de escala e propõe no seu lugar uma metodologia plana. A "escala absoluta” é criticada porque sociólogos "críticos" usam o conceito de forma dedutiva e a priori para selecionar "atores relevantes" para estudo e ignoram os outros atores. Isso resulta numa queima de etapas em uma pesquisa e a inclusão de apenas alguns atores de uma rede maior de relações, que leva a conclusões prematuras, gera resultados tendenciosos e indica políticas equivocadas. No lugar de hierarquias de relações, Latour propõe associações de formata estrela, que não podem ser ordenadas ou empilhadas, são múltiplas, não apenas global ou local e só diferem no seu alcance e na sua influência. Ele cita como exemplo o enorme alcance do setor financeiro da Wall Street.

$\mathrm{Na}$ segunda parte do livro, porém, Latour afirma que não tem nada contra a "escala relativa”, pelo contrário, representa aquilo que os atores conseguem na prática, de forma que o ator em si não é achatado, só o procedimento de investigação das redes em questão. Latour também sustenta que deve usar o conceito de poder mais cuidadosamente, mas isso não significa que ele nega a existência de uma grande pirâmide social, caracterizada por desigualdade de cima a baixo. Para Latour a ontologia plana representa um método mais apurado para chegar empiricamente a relações de poder realmente existentes no mundo e não idealizado de antemão, sejam elas verticais ou horizontais.

Finalmente, Latour (2013) observa que as associações envolvendo a governança e o capital social são quase invisíveis e demandam muito esforço para serem detectados, que é bastante pertinente aos casos apresentados aqui na Amazônia e no Pantanal tratando territórios de população "tradicional” no país. Quanto aos territórios étnicos, como empirista radical, Latour detesta o conceito de "identidade" na maneira que é 
formulado por sociólogos críticos. Para Latour, na Sociologia Crítica utiliza-se identidade como se fosse uma essência permanente interna de um sujeito aparte, um sercomo-ser, que é, e não, como um ser-como-outro, um quase-sujeito, identificado por sua articulação em redes externas compostas de quase-sujeitos e quase-objetos, que tem interesses intensos em comum. Para as pessoas envolvidas, a identidade pode parecer mais durável, assegurada e enraizada, mas isso é uma ilusão, pois atrapalha detectar e construir redes políticas mais amplas.

\section{Métodos para reagrupar o social na Amazônia e no Pantanal}

Os métodos relacionais foram usados em pesquisas realizadas na Amazônia e no Pantanal, mas geraram resultados apontando situações opostas quanto à relação entre indígenas e ribeirinhos nos dois casos que ilustram a abordagem híbrida das três perspectivas teóricas apresentada acima.

\section{Amazônia Central e Ocidental}

A avaliação de movimentos étnico-territoriais na Amazônia se baseia em pesquisa antropológica e geográfica realizada desde 1975. Através dos anos o autor teve contato com quase todo tipo de ator social presente na região, variando desde os ameríndios ianomâmis e ie'quanas até os agricultores urbanos de Manaus. A pesquisa de 1975 junto aos ianomâmis e aos ie'quanas em Auaris (RR) foi realizada dentro de um projeto maior da UnB e da FUNAI que visava estabelecer uma reserva indígena. O estudo foi uma etnografia clássica sobre dois grupos de ameríndios que na época ainda tinham economia e sociedade tribais, havendo apenas contatos seletivos com o mundo externo.

No levantamento de atores locais chegou a contatar 662 famílias rurais, investigando disputa de posse e violência, técnica agropecuária, tendências de desmatamento, comercialização de produtos agrícolas, fontes de renda, organização comunitária, articulação a diferentes escalas políticas, acesso aos serviços públicos, história migratória, condições de vida, relações familiares, religião e visão do mundo. Também foram entrevistados líderes indígenas, ribeirinhos e de colonos, religiosos, políticos municipais e estaduais e técnicos da Fundação Nacional do Índio (FUNAI), do Instituto Brasileiro do Meio Ambiente e dos Recursos Naturais Renováveis (IBAMA), 
do Instituto Chico Mendes de Conservação da Biodiversidade (ICMBio) e do Instituto Nacional de Colonização e Reforma Agrária (INCRA).

A intenção era investigar de baixo para cima as redes de governança na região, confrontando diferentes escalas verticais do poder (Figura 3). Contudo, na maneira em que as investigações avançarem ficou cada vez mais evidente que os métodos verticais ocultavam sérias contradições horizontais entre os movimentos de diferentes atores sociais ocupando a mesma escala local.

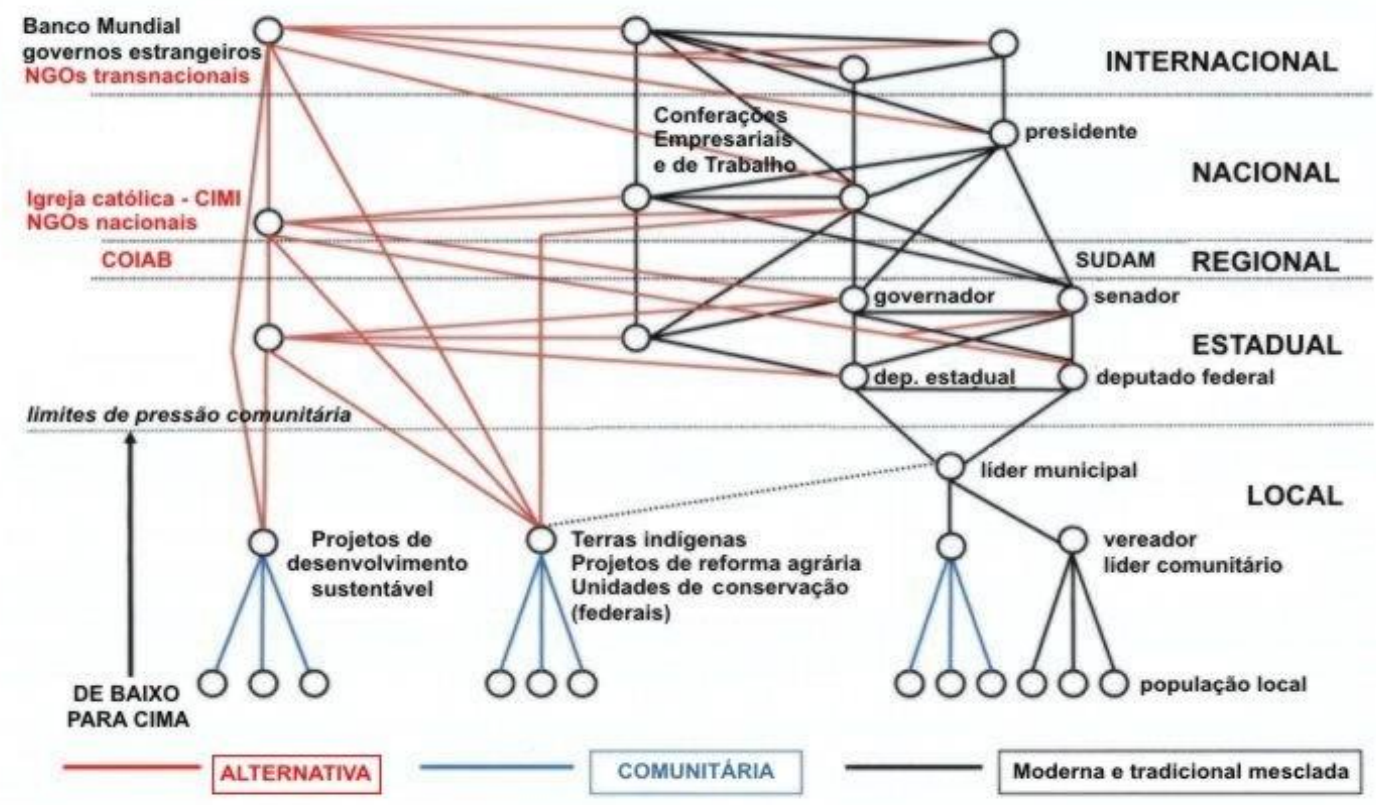

Figura 3 - Relações políticas verticais contornando escalas ocultam conflito horizontal na Amazônia. Fonte: Adaptado de Bicalho, Hoefle (2010) e Hoefle (2000; 2006a).

Em publicações anteriores que analisavam os diferentes movimentos sociais da Amazônia, tratados separados um a um, todos pareciam ser bem sucedidos (HOEFLE, 2000, 2006a; BICALHO, HOEFLE, 2010). Contudo, a partir de 2005, foi ficando cada vez mais evidente que, quando visto em interação, isto é de forma horizontal, os atores pobres da Amazônia acabam competindo entre si por território, resultando num jogo de soma zero, no qual um grupo avança ao custo dos outros. Sempre tive dúvidas sobre a noção ambientalista da "união dos povos da floresta", mas nunca podia imaginar a dimensão do conflito direto entre movimentos indígena, ribeirinho e de colono que surgiu nas primeiras décadas do século XXI. 
Alto Rio Paraguai no Pantanal

Os mesmos métodos foram utilizados em pesquisa de campo realizada em 2015, junto aos ribeirinhos que vivem no trecho do Rio Paraguai situado na divisa do Mato Grosso e do Mato Grosso do Sul. Esta investigação, por sua vez, fez parte de uma pesquisa mais ampla sobre o Pantanal desenvolvida desde 2002 por pesquisadores da Universidade Federal do Mato Grosso do Sul e da Universidade Federal do Rio de Janeiro. A data do trabalho de campo em 2015 foi programada para coincidir com uma audiência pública do Ministério Público Federal de Corumbá, que visou mediar um conflito entre as unidades de conservação ambiental, públicas e privadas, e a população ribeirinha.

Antes da realização da audiência pública foram entrevistadas 32 famílias ribeirinhas, de um total de 64 famílias, distribuídas em quatro comunidades próximas a Serra do Amolar. Também foram entrevistados o gerente e quatro trabalhadores rurais de uma das enormes reservas particulares. Aos entrevistados foi aplicado um questionário detalhado sobre a pesca e uso de outros recursos naturais, sistemas agropecuários, grau de articulação ao mercado, relações de trabalho, estrutura familiar, atuação do Estado na provisão de serviços básicos e qualidade de vida em geral. O trabalho de campo terminou com a participação na audiência pública que determinou o destino dos ribeirinhos. Na audiência a equipe de pesquisadores observou a atuação dos atores locais e extralocais que se distribuíram em duas redes rivais, uma de conservação biocêntrica e outra de conservação socioecológica.

\section{Ameaças globais e estratégias de permanência no lugar de populações “tradicionais"}

$\mathrm{Na}$ virada do milênio, quando se celebrava a globalização envolvendo cidades mundiais informatizadas e cidadãos conectados em rede, Edelman (2001), Harrison (1999) e Sökefeld (1999) notaram que povos nativos e outras populações rurais pobres se mobilizavam no sentido contrário, de fechar seus territórios à penetração de interesses globais, exatamente porque estes representam ameaças ao seu modo de vida.

A expansão do agronegócio, resultando em “land-grabbing” (grilagem de terras), é a mais óbvia ameaça global (BORRAS JR. et al., 2011; SCOONES et al., 2013). A contraurbanização, o turismo rural e o ecoturismo também podem promover a 
expropriação de agricultores pobres por indivíduos urbanos querendo "consumir o rural e a natureza" (MURDOCH, 2006; FIELDING, 2000; WOODS, 2011).

O movimento global pela conservação representa uma terceira ameaça à população pobre do campo. ONGs ambientalistas pressionam pela criação de corredores ecológicos ligando unidades de conservação, muitas vezes localizadas em zonas de montanhas e remotas, onde ainda existem extensões maiores de floresta, exatamente nos refúgios históricos de populações rurais marginalizadas. Contra essas, na implantação de unidades de conservação integral os gestores promovem o cerceamento por natureza, visando expulsá-las de terras ocupadas há gerações (ADAMS, MULLIGAN, 2003; BÜSCHER, FLETCHER, 2018; DOWIE, 2009; JACOBY, 2014, PEET et al., 2011).

Perante as ameaças ao seu modo de vida, paralelamente aos movimentos da conservação global liderados por cidadãos urbanos do Primeiro Mundo, nas últimas décadas surgiram vários movimentos de permanência entre populações tribais e campesinas históricas da África, Ásia e América Latina que residem dentro e no entorno das unidades de conservação. Lutando contra sua retirada e as restrições de suas atividades de sustento, os movimentos locais acabaram provocando mudanças fundiárias semelhantes a uma reforma agrária. De 1985 a 2000 foram transferidos formalmente territórios ou direitos à utilização comunitária de recursos naturais de mais de 200 milhões de hectares de floresta no mundo (LARSON et al., 2010).

Com o tempo, os movimentos promoveram sua versão de "globalização", evoluindo para abranger escalas de atuação mais amplas em redes globais, culminando em três congressos mundiais sobre reforma fundiária e governança florestal, realizados no Brasil em 2007, em Camarões em 2009 e na Indonésia em 2011, que visaram promover sistemas de manejo florestal comunitário como uma estratégia viável de alcançar crescimento econômico com baixo impacto carbônico, conservação florestal e redução de pobreza rural (BICALHO, HOEFLE, 2015; CHARNELY, POE, 2007; COLCHESTER, 2008; MOLNAR, 2011; RRI, 2011).

\section{Contradições entre conservação ambiental e territórios étnicos na Amazônia}

Após a promulgação da Constituição de 1988, a Amazônia se tornou um dos grandes laboratórios mundiais de política alternativa com base na governança verde de baixo para cima. Uma multidão de atores sociais organizados em redes comunitárias, municipais, estaduais, regionais, nacionais e globais passou a interagir e disputar o 
destino da floresta amazônica. Ao longo de anos pesquisando as redes, à maneira que o contato com a grande diversidade de atores na Amazônia foi acumulando e a “amostragem espacial” alargando, aos poucos, percebi que surgia uma situação de grande injustiça contra a população ribeirinha histórica. Esta era invisível ou mesma ignorada pela maioria dos estudiosos da Amazônia, mal entendida por gestores ambientais e discriminada em ações sociais do governo federal. Instalou-se um jogo de soma zero entre atores locais que só recentemente está cedendo lugar para cooperação entre os mesmos.

COIAB como movimento político bem-sucedido

A Coordenação das Organizações Indígenas da Amazônia Brasileira faz parte dos movimentos contra a globalização visando afastar as ameaças do agronegócio, da contraurbanização e da preservação biocêntrica. A ONG é o mais bem sucedido movimento social da Amazônia e talvez do Brasil. Liderados pelos ameríndios mais “aculturados", principalmente os tucanos do estado do Amazonas e os macuxis do estado de Roraima, e ajudados por uma aliança impressionante de ambientalistas, antropólogos e religiosos brasileiros e estrangeiros, em 1989, os indígenas da Amazônia fundaram a COIAB. Com sede em Manaus, na final da década de 1990, a COIAB já abrangia 56 organizações, representando 163 povos e aproximadamente 204.000 indígenas nos nove estados da Amazônia Legal (COIAB, 1991-1998). Hoje a organização engloba 75 organizações, representando 160 povos, com cerca de 440.000 indígenas residindo em terras somando 110 milhões de hectares (COIAB, 2020; FUNAI, 2018) (Figura 4). 


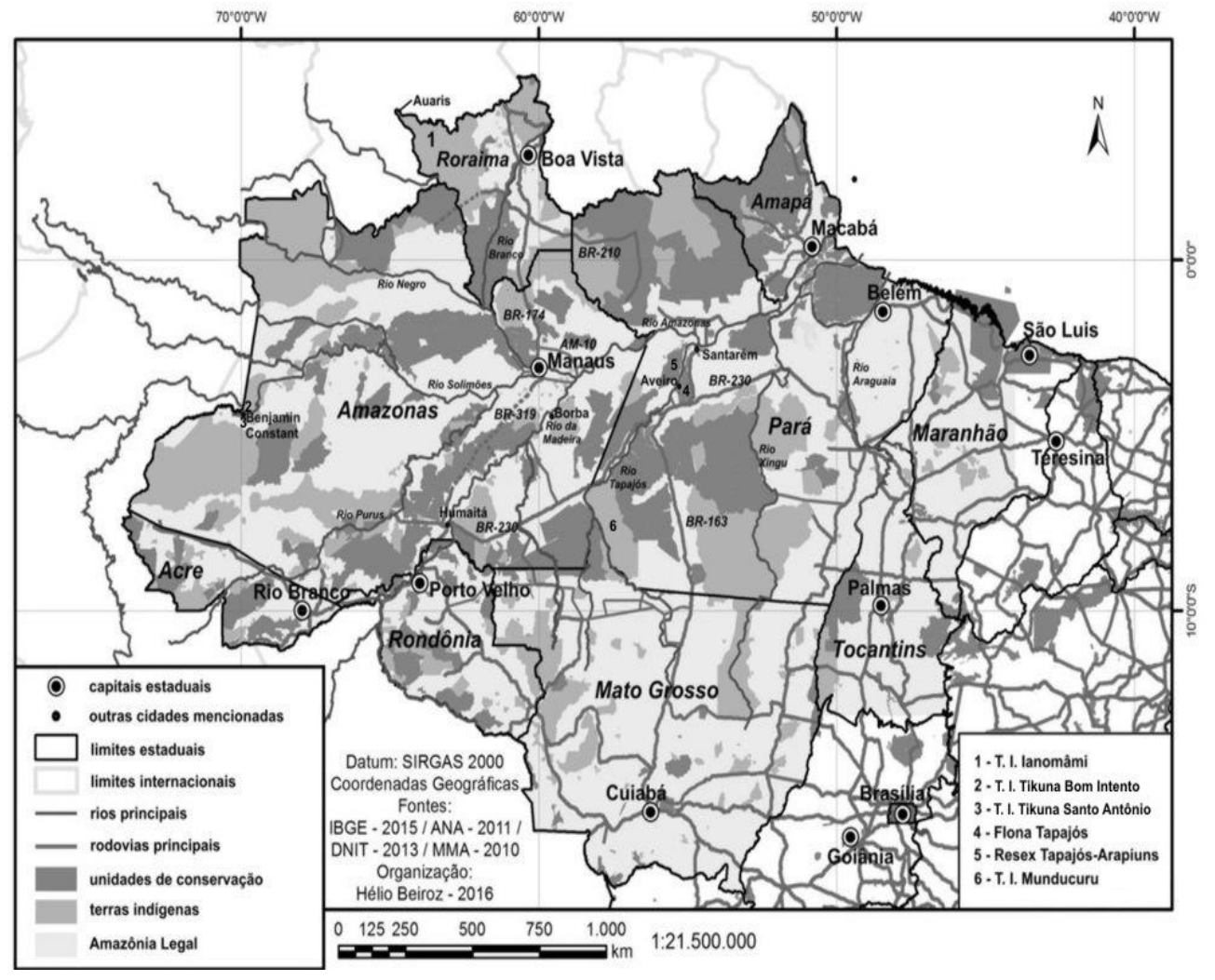

Figura 4 - Terras indígenas e unidades de conservação na Amazônia Legal. Fonte: Adaptado de COIAB (2020) e FUNAI (2018), 2020.

Um indicador do sucesso dos indígenas é a reversão de tendências demográficas anteriores, fazendo com que a população indígena tenha voltado a crescer depois de séculos de declínio. De um total de aproximadamente três milhões de ameríndios que existia em território brasileiro em 1500, o número de ameríndios caiu para 70.000 em 1957, antes de recuperar para 817.962 em 2010 (AZEVEDO ad pud FUNAI, 2018). Antes de 1990, os indígenas e seu padrão de aldeamento pareciam destinados a desaparecer na maneira que foram sendo exterminados ou assimilados à sociedade nacional através de um processo linear de aculturação cabocla (cf. HARRIS, 1998; SISKIND, 1973). Após 1990, porém, houve uma crescente valorização étnica entre a população de ascendência indígena. Após a demarcação de enormes áreas, ser considerado indígena tutelado pela FUNAI passou a ter suas vantagens: garantia de acesso a terra para trabalhar sem a interferência das elites regionais, proteção da concorrência desleal do agronegócio e a aparente liberação das limitações impostas pelos órgãos ambientais IBAMA e ICMBio, bem como acesso a escolas indígenas e a serviços de saúde que possam ser superiores aos serviços carentes prestados à população ribeirinha na Amazônia. 
Destilando complexidade cultural em tradição reinventada?

Ao longo dos anos de pesquisa de campo na Amazônia, comentários curiosos e experiências inesperadas foram se acumulando e somando dúvidas sobre o impacto do sucesso do movimento indígena sobre a população ribeirinha. Uma primeira dúvida surgiu em pesquisa realizada próxima à cidade de Benjamin Constant (AM) em 2005. Na época da homologação da T.I. Tikuna de Santo Antônio foram retirados ribeirinhos presentes e o INCRA os assentou numa nova estrada aberta e, posteriormente, pessimamente mantida. O local é afastado do Solimões e da vida a qual os ribeirinhos eram acostumados. Os solos são pobres e na época da safra durante as chuvas os produtores não conseguiam comercializar quase nada porque a estrada fica intransitável. Em decorrência, seu padrão de vida decaiu para um patamar dos mais pobres encontrados em toda minha experiência na Amazônia.

O que afinal é um ribeirinho ou caboclo da Amazônia para merecer este tratamento? Hiraoka definiu o caboclo como "um ameríndio destribalizado, que é descendente de casamento entre indígena e europeu, sendo produto de uniões com pais de origens étnicas e nacionais das mais variadas" (1992, p. 135, traduzido aqui). Este autor também observou que, apesar de constituir a maioria dos habitantes da Amazônia, os ribeirinhos são invisíveis em pesquisa acadêmica e em política governamental, visto que esta se concentra ou nos ameríndios na Amazônia preservada ou nos colonos da fronteira de expansão agrícola. Na época, isso ocorria porque a população ribeirinha era dispersa, não tinha representação em foros regionais, nacionais e internacionais e não tinha um estilo de vida exótica. Em outras palavras, para os acadêmicos, os ribeirinhos não eram interessantes para estudar e não se encaixavam nos tipos idealizados weberianos que fundamentam a pesquisa científica na Amazônia.

Quando Hiraoka fez essas observações o foco de pesquisa acadêmica já estava mudando. Seu próprio trabalho fez parte de um livro entre outras publicações sobre ribeirinhos que apareceram após 1990: Chibnik (1994), Harris (1998), Nugent (1993, 2002) e Padoch et al. (1999). A visibilidade política dos ribeirinhos também melhorou após a promulgação da Constituição de 1988, que descentralizou a política no país e concedeu o direito de voto a todos, incluindo grande número de ribeirinhos analfabetos. No novo contexto, nutrido por décadas pela ala da Teologia da Libertação da Igreja Católica, o movimento comunitário decolou. Os ribeirinhos passaram a obrigar políticos municipais e estaduais a atender, mesmo que precariamente, suas ansiedades por serviços 
de educação, saúde, eletricidade, telefone e água tratada (BICALHO, 2009, BICALHO, HOEFLE, 2010; HOEFLE, 2000). Como os indígenas, os ribeirinhos construíram extensas redes-ator e agência política. Também não são os camponeses com mentalidade de subsistência que os planejadores, ambientalistas e vários acadêmicos acham ser. $\mathrm{Na}$ verdade, sua agricultura é articulada a mercados regionais e a escala varia de acordo com as limitações do ambiente local de várzea ou de terra firme à beira de rio e com a proximidade aos mercados dos poucos centros urbanos na Amazônia preservada (veja BICALHO, 2010; BICALHO, HOEFLE, 2008; HOEFLE, 2017).

Com estas dúvidas em mente, em 2010 e 2013, ao estudar o movimento ribeirinho de resistência aos órgãos ambientais atuando na Floresta Nacional do Tapajós e na Reserva Extrativista do Tapajós-Arapiuns, o pesquisador se deparou com uma situação de conflito que surgiu entre este movimento e o movimento de estabelecer terra indígena no mesmo espaço. A FLONA Tapajós é uma das mais antigas florestas nacionais da Amazônia, datando de 1975. Foi criada no contexto do Programa de Integração Nacional dos governos militares, sendo inicialmente administrada pelo IBDF, mais tarde substituído pelo IBAMA e hoje pelo ICMBio. Desde sua criação é uma área de conflito ambiental e fundiário envolvendo, por um lado, a população tradicional ribeirinha há séculos residente à beira do rio Tapajós e a população de assentamentos rurais do INCRA, criados nos anos 1970, ao longo da BR-163 e, por outro, os órgãos ambientais (Figura 5).

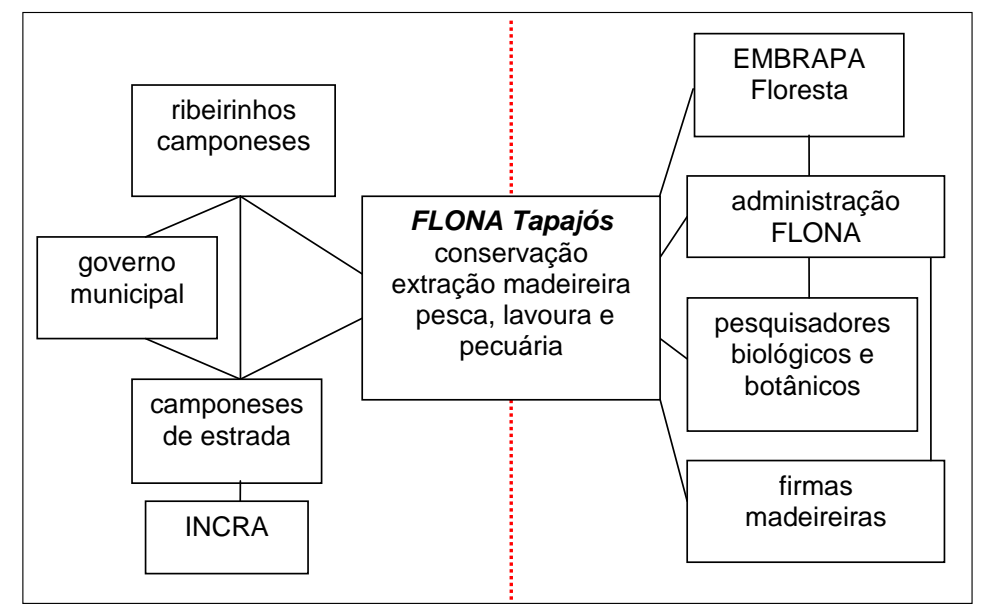

Figura 5 - Embate com biocentrismo: agrupamentos rivais na Flona Tapajós - 1975 a 1996

O confronto socioambiental levou à criação da primeira experiência de gestão comunitária de exploração sustentável de madeira no país, que, inclusive, ajudou a mudar a política socioambiental dos órgãos ambientais. Houve o reconhecimento formal de uma 
área de residência e acesso a uma faixa de terras de dez quilômetros de largura ao longo do rio Tapajós para a prática do extrativismo e da agricultura de "subsistência". A população também ganhou uma concessão de vinte anos do direito de uso exclusivo de recursos madeireiros e não madeireiros em outras áreas da FLONA (Figura 6).

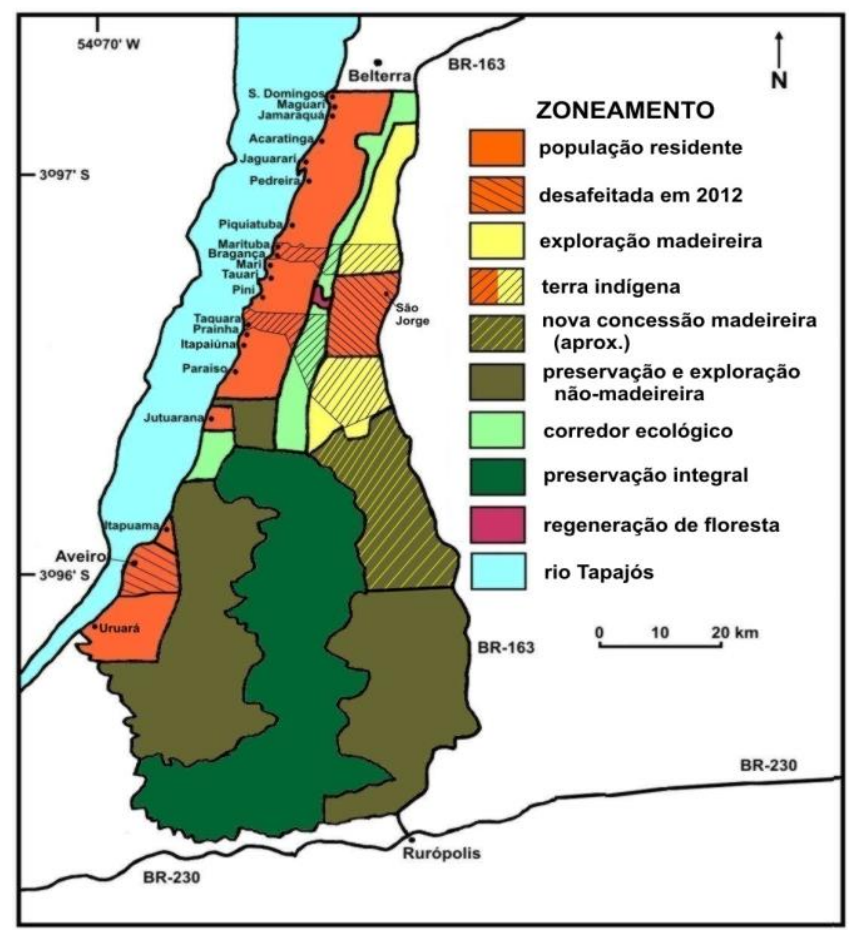

Figura 6 - Zoneamento socioambiental da FLONA Tapajós. Adaptado de: IBAMA (2005), ISA (2014),

À base de organização comunitária formaram-se associações nas vinte comunidades da FLONA. O reagrupamento das associações em três associações intercomunitárias, por sua vez, permitiu a criação da Cooperativa Mista FLONA Tapajós Verde (COOMFLONA) em 2005, visando a extração e comercialização de madeira e dos produtos não madeireiros da floresta. A cooperativa focou na extração de madeira, mesmo se também incentivou as atividades não-madeireiras como queriam as ONGs parceiras. Várias destas atividades já foram exploradas no passado e deixadas de lado porque geraram renda insuficiente (veja BICALHO, HOEFLE, 2015 para maiores detalhes).

O surgimento de movimento pela criação de terras indígenas na FLONA, por sua vez, ameaçou o empreendimento dos ribeirinhos. Dentro dos limites da FLONA existem três comunidades de descendentes dos ameríndios mundurucus. Apesar do fato que a T.I dos mundurucus hoje é localizada a 400 quilômetros rio acima em Jacareacanga, historicamente havia indígenas deste grupo no baixo Tapajós. A sede do município de 
Aveiro teve suas origens no século XVIII numa aldeia de mundurucus (IBGE, 2016). Hoje há por volta de 500 pessoas morando nas aldeias de Bragança, Marituba e Taquara, que em 2017, tiveram suas terras homologadas, passando para a jurisdição da FUNAI (ICMBio, 2014, VAZ FILHO, 2011). Agora os indígenas chamam seu conjunto de moradias de "aldeia" e não mais de "comunidade". Para os ribeirinhos, o segundo termo tem alta carga de simbolismo remetendo ao movimento coletivo pela terra, recursos e serviços públicos. Ao utilizarem o termo "aldeia" no lugar de "comunidade" os indígenas sinalizam seu desligamento do movimento maior (Figura 7).

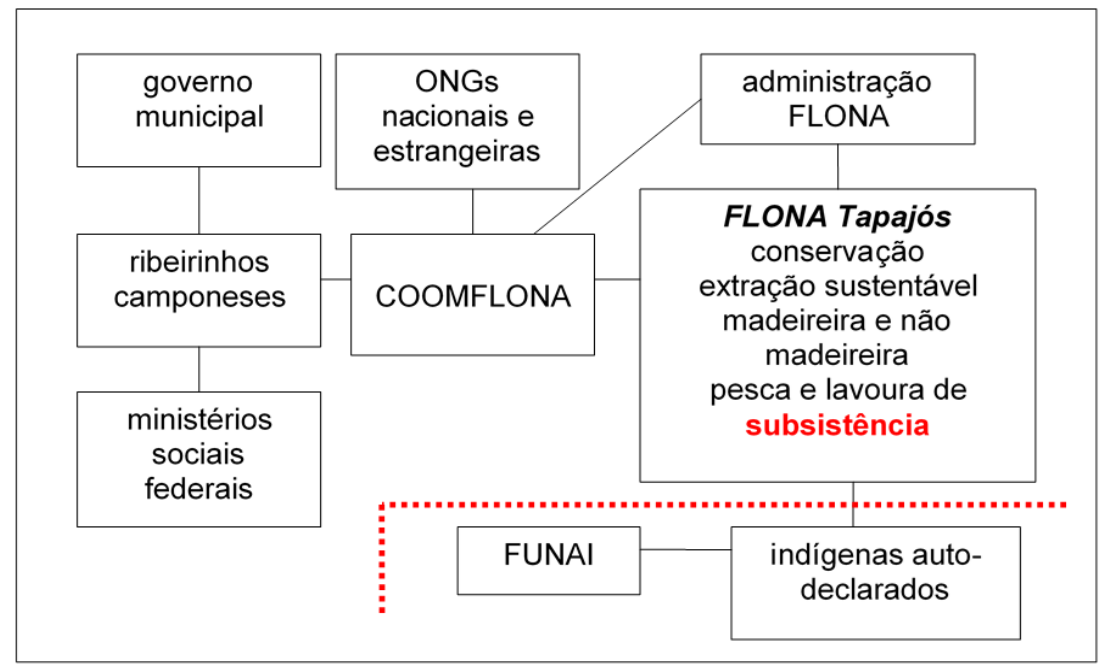

Figura 7 - Embate entre a rede de conservação sócio-ecológica e as terras indígenas após 2010

As terras reivindicadas pelos indígenas incluem não somente a faixa de dez quilômetros de largura situada ao longo do rio Tapajós, mas também uma faixa de trinta quilômetros que atravessa a FLONA até a BR-163. Sob o pretexto de serem terras ancestrais de caça, quando se passa dos dez quilômetros para dentro da FLONA, a faixa abre em leque para incluir quase toda a área de exploração florestal comunitária da cooperativa dos ribeirinhos, que fica por trás de todas as comunidades. O ICMBio evitou um conflito entre os dois grupos, concedendo outra área para os ribeirinhos, duas vezes maior mais a sul na FLONA, e a COOMFLONA concordou em treinar os indígenas a explorar de forma coletiva a área que ganharam.

As aldeias também receberam escolas indígenas, em primeiro momento arcadas pelo governo municipal, que serão substituídas depois por escolas oficiais da FUNAI (VAZ FILHO, 2011). Essas ensinam a língua ancestral que só alguns idosos ainda falam, como também costumes há muito esquecidos. Um estudo cita o conceito de tradição reinventada do Hobsbawn para justificar isso (COSTA et al., 2013), mesmo que esse 
autor tenha sido bastante ambivalente sobre este fenômeno (1969, p. 170). Reaprender a cultura dos ancestrais pode ser ótimo para a autoestima, mas também pode ser deturpado, como no caso de embarcações turísticas de Santarém trazendo turistas para ver "dança tribal”.

O problema com tudo isso é que as pessoas das outras comunidades da FLONA Tapajós são praticamente indistinguíveis dos indígenas autodeclarados. Em outras palavras, ambos os grupos demonstram biótipo e comportamento híbrido. Em 2010, na conversa com um líder comunitário, eu fiquei admirado como o homem tinha um comportamento quase idêntico aos ie'quanas estudados quarenta anos antes. Enquanto eu escutava suas reclamações sobre os indígenas da aldeia ao lado, notei que, além da forte ascendência indígena dos seus traços físicos, ele estava deitado numa rede tipicamente indígena. Em vez de sentado na rede ou deitado no diagonal atravessando a rede, ele conversava comigo deitado de lado, falando pelos buracos da rede, de maneira que me lembrava das horas de conversas com Waipo meu velho amigo ie'quana. Intrigado com a cena, eu pedi licença para tirar um retrato dele, mas aí ele se comportou como um ribeirinho: ele levantou, vestiu uma camisa e fomos do lado de fora para tirar um retrato convencional, com pose, junto a sua mulher, em frente da casa, que inclusive tinha propaganda política na parede externa (Figura 8).

Nas terras indígenas legalmente constituídas só é permitida a presença de indígenas, e os "não-indígenas" são obrigados a sair. Todavia, é extremamente difícil bater uma linha divisora entre "cultura indígena" e "cultura ribeirinha" e a insistência em fazê-la gera intenso conflito nas comunidades ribeirinhas transformadas em aldeias indígenas, entre as famílias vizinhas e até entre membros da mesma família. Ignorando a complexidade étnica e até mesmo as décadas de luta política dos ribeirinhos contra sua retirada das unidades de conservação, Peixoto et. al (2012) decretam que um indígena é um caboclo que ficou politizado, sugerindo que os ribeirinhos são politicamente passíveis. 


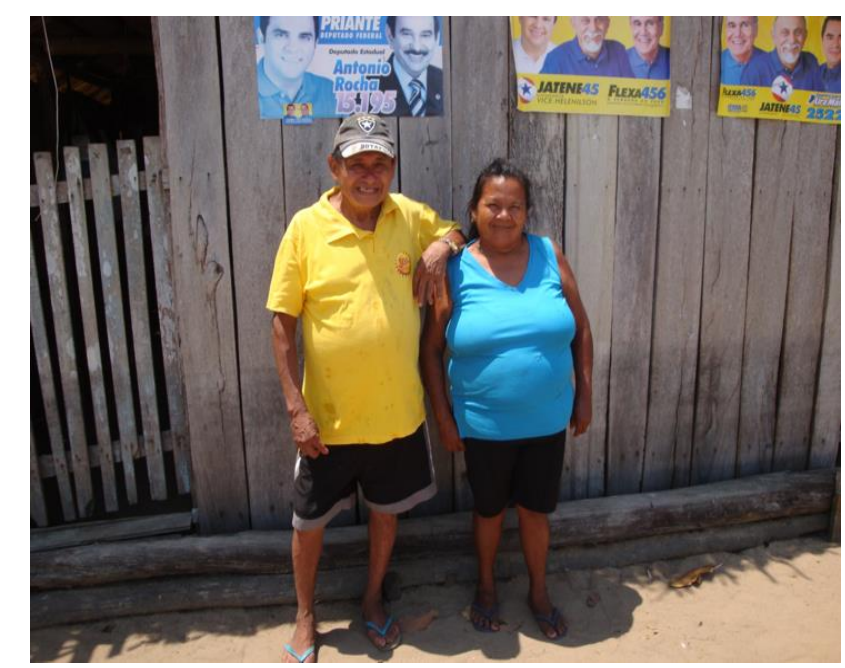

Figura 8 - Ribeirinhos com identidade cultural híbrida. Fonte: Pesquisa de campo (2010).

Os conflitos étnicos são ainda mais presentes na Reserva Extrativista de TapajósArapiuns. Durante os anos 1990, pressionado por firmas madeireiras de Santarém, surgiu um movimento de ribeirinhos do rio Arapiuns e do lado ocidental do rio Tapajós pleiteando ao IBAMA a implementação de uma reserva extrativista, que foi criada em 1998 com uma área de $6.775 \mathrm{~km}^{2}$. O movimento pela RESEX se espelhou no movimento da FLONA, e de fato, em vários momentos críticos no passado, moradores do outro lado do Tapajós ajudaram seus parentes, compadres e amigos do movimento da FLONA. Vaz (2010) produziu um estudo detalhado da política de identidade étnica inserida no movimento pela RESEX que mostra que até 2002, a população em geral apoiava a criação da RESEX como também das terras indígenas. Vaz alega que o divisor das águas foi uma concessão de recursos do governo finlandês destinada à implementação de um projeto de exploração florestal comunitária semelhante ao sistema da FLONA Tapajós. Segundo esse autor, surgiram problemas com corrupção envolvendo altos funcionários do IBAMA e houve o veto do governo finlandês à criação de terras indígenas, resultando na polarização da população entre as pessoas a favor e contrárias às terras indígenas dentro da RESEX.

Vaz tem ascendência indígena maytapu, durante anos foi frade franciscano atuando entre a população da RESEX, ativamente engajado na criação das terras indígenas, em 2010 defendeu uma tese de doutorado sobre o assunto e atualmente é professor da Universidade Federal do Oeste do Pará, sediada em Santarém. Na sua ótica, a população a favor do projeto de manejo florestal comunitário é "economicista" porque seu interesse pelo projeto é ganhar dinheiro, uma afirmação ingênua. Quando se trata da população do baixo rio Tapajós, como também a do baixo rio Madeira, deve ser lembrado 
que há séculos os dois rios são importantes meios de logística regional. A população ribeirinha/indígena não vive isolada numa economia tribal, do tipo que o pesquisador estudou em 1975, e como vimos acima, através do tempo, perdeu-se muito de sua cultura indígena original. Ambos os rios participaram do ciclo da borracha, que no rio Tapajós foi mais importante exatamente no lado ocidental do rio, onde tem a RESEX atualmente. Ainda podem ser encontradas seringueiras nas comunidades ribeirinhas que continuaram sendo exploradas, em maior ou menor escala, durante quase todo o século XX, muito depois do auge do ciclo do látex. Hoje há certa expansão da atividade em função de novas oportunidades na eco-economia mundial (veja BICALHO, HOEFLE, 2015, para maiores detalhes). Em função dos diferentes ciclos econômicos, o baixo Tapajós recebeu várias levas de nordestinos (também com expressiva ascendência indígena, porém antiga) que casaram com a população ribeirinha e assimilaram costumes locais (dirija-se a HOEFLE, 2006b; PARKER, 1985).

Na verdade, os característicos indígenas que Vaz (2010) apresenta também são ribeirinhos e alguns até não-indígenas, como no caso da farinha de mandioca. A farinha representa uma forma de estocar mandioca visando sua comercialização e é um dos poucos produtos agrícolas que aguentam as longas viagens por rio até os mercados consumidores regionais. Já os indígenas estudados pelo autor no noroeste de Roraima ou comiam macaxeira in natura, no caso dos ianomâmis, ou beiju de mandioca feito todo dia, no caso dos ie'quanas. Na ocasião da pesquisa de campo em Auaris, o autor assistiu um ie'quana, tido como mais moderno, fazer farinha pela primeira vez na aldeia, possivelmente para impressionar o pesquisador. O processo de transformação em farinha leva muito mais tempo e gasta maior quantidade de lenha do que ralar mandioca e torrar uma pequena quantidade de beiju diariamente.

Assim sendo, os ribeirinhos com ascendência indígena do Tapajós não são ameríndios tribais que não utilizam dinheiro, nem são camponeses com mentalidade de subsistência, ou qualquer outra idealização acadêmica, que poderiam ficar satisfeitos apenas com a afirmação do seu orgulho étnico. Também querem acesso à terra e aos recursos para ganhar uma renda suficiente para viver com dignidade, sem a interferência indevida de órgãos ambientais. Isso é exatamente o objetivo maior do movimento global de populações da floresta (COLCHESTER, 2007; LARSON, et al., 2010; MOLINAR, 2011). Os modelos simplistas de segregação étnica, implementados pelo governo federal durante as primeiras décadas do século XXI, agiram no sentido contrário, supondo que 
a população vive da "subsistência" porque quer, uma idealização tão divorciada da realidade quanto à opinião semelhante entre técnicos dos órgãos ambientais.

\section{A complexidade cultural da Amazônia}

É fácil distinguir os ameríndios tribais da Amazônia dos colonos pobres do Nordeste e dos fazendeiros sulistas porque os três grupos possuem sistema de uso da terra, padrão de vida, ética ambiental, visão de mundo e cultura bem diferentes. Os primeiros praticam caça, coleta e agricultura sustentável de pousio longo em pequena escala, gerando um pequeno excedente, não têm uma economia monetária, até pouco tempo atrás moravam em maloca e têm ética ambiental homo-ecocêntrica e visão do mundo animista.

Os nordestinos são camponeses móveis situados na ponta de expansão da fronteira agrícola em floresta primária. Praticam a agricultura insustentável de pousio curto ou sem pousio e a pecuária de pequena escala, que geram um excedente para comprar o que não produzem. Moram em casas simples de pau e pique ou de tijolo. Têm visão do mundo cristã espiritualmente bifurcada e ética ambiental homocêntrica, que os levam a serem descrentes do folclore de espíritos encantados da floresta e dos rios.

Pecuaristas sulistas, por sua vez, se deslocam logo atrás dos nordestinos na fronteira agrícola, compram ou apossam por um processo de "land grabbing" terras já abertas pelos nordestinos, instalam fazendas de gado e depois as vendem por um bom lucro. Outros sulistas vêm por trás destes, na fronteira de commodities, compram as fazendas e plantam arroz, milho e soja em escala comercial, podendo também praticar uma pecuária bovina mais intensiva. Os dois grupos de sulistas têm ética ambiental egocêntrica e visão de mundo altamente secular. Eles possuem moradias de alto nível e recriam sua cultura distinta em centros de tradição gaúcha (veja BICALHO, HOEFLE, 2008, 2015; HOEFLE, 2013, 2017).

Vimos que não é fácil distinguir os ribeirinhos dos indígenas que residem ao longo dos rios principais da Amazônia. Os ribeirinhos têm forte ascendência indígena, praticam a mesma agricultura, possuem uma cultura material quase idêntica e compartilham a mesma visão de mundo espiritualmente bifurcada cristã mesclada com vários elementos encantados. Assim sendo, para superar a semelhança é necessária a reinvenção de cultura para identificar os autodeclarados como "indígenas autênticos", devidamente depurados para poderem viver em um território segregado. 
Os ribeirinhos também sofreram com as políticas preservacionistas federais, sendo pressionados para sair de suas terras, ocupadas há gerações, para dar lugar a unidades de conservação integral nas quais só é permitida a presença da equipe de fiscalização, cientistas realizando pesquisas biológicas e talvez ecoturistas, ou seja, pessoas da cidade e não pobres do campo. Também nesta questão, os acadêmicos têm sua contribuição à injustiça ambiental em função da divisão de trabalho científico em vertentes biofísicas e humanas, fazendo com que, quem implementa as políticas de conservação possui treinamento nas ciências biológicas, mas é despreparado para lidar com complexidade humana.

As limitações ambientais impostas, por sua vez, reforçam o movimento de criação de terras indígenas como estratégia de garantir o acesso à terra e aos recursos sem a interferência do IBAMA e do ICMBio, acerbando, dessa forma, o conflito étnico. Um meio termo nesta complexidade cultural toda é a estratégia territorial do Estado do Amazonas, que criou reservas de desenvolvimento sustentável (RDS) em praticamente todas de suas bacias fluviais, visando proteger a população ribeirinha contra a incursão de interesses madeireiros e da pesca de grande escala. Isso foi fruto do movimento político promovido pelos ribeirinhos desde os anos 1990 (veja HOEFLE, 2000; BICALHO, HOEFLE, 2010; PINTO, 1997; 2004).

Contudo, como sempre acontece na Amazônia, em janeiro de 2019, assumiu um novo presidente que prometeu alterar drasticamente a política territorial federal, suspendendo a criação de novas terras indígenas e unidades de conservação e abrindo as que existem para exploração mineral, madeireira e agrícola. Esta mudança radical de política sócio-ambiental certamente terá impacto negativo nas estratégias de permanência da população histórica da Amazônia, superando qualquer conflito que existia até há pouco entre indígenas e ribeirinhos. Em reação ao novo jogo de soma zero para todos os atores sociais históricos da Amazônia, surgem exemplos de aliança entre indígenas e ribeirinhos como ocorre no médio Tapajós. Confrontados com a inação estatal, indígenas e ribeirinhos fazem em conjunto a autodemarcação de seus territórios contra o inimigo em comum, os madeireiros, garimpeiros e pecuaristas ávidos pela volta do velho desenvolvimento predatório. 


\section{Contradições entre conservação ambiental e territórios étnicos no Pantanal}

O conflito entre modelos de conservação no Pantanal é mais simples etnicamente do que o da Amazônia tratado acima, pois não envolve disputa entre grupos sociais locais por um mesmo território. Pelo contrário, o modelo socioecológico que surgiu entre os ribeirinhos envolve desde o início uma aliança entre indígenas guatós e os ribeirinhos exatamente porque ambos constituem pequenas minorias étnicas numa região maior dominada pelo agronegócio.

\section{A conservação ambiental no Pantanal}

O Pantanal é um dos maiores conjuntos de terra sazonalmente alagada do mundo. Como no caso da Amazônia, o Pantanal possui uma beleza espetacular e apresenta flora e fauna exuberante que atraem turista nacional e estrangeiro. Em décadas recentes o bioma tem sido o objeto de políticas de preservação ambiental promovidas por organizações governamentais e não-governamentais. O Parque Nacional do Pantanal Matogrossense foi criada em 1981, e a partir dos anos de 1990, foram implementadas várias Reservas Particulares de Patrimônio Natural, que juntas ao PARNA formaram uma rede de unidades de conservação integral. Em parceria com as ONGs a Nature Conservancy e a Ecotrópica, foram criados corredores ecológicos em torno do PARNA que se estendem para o sul da Serra do Amolar, totalizando uma área com 276.087 hectares (Figura 9).

No ano de 2000, o conjunto da Serra do Amolar, localizado na parte mais alagada do Pantanal foi inscrito no Patrimônio Natural Mundial pelo UNESCO (MMA, 2016). A preservação do bioma é tão importante para a biodiversidade global que a ONG $W$ orld Wildlife Fund elegeu o Pantanal como uma de suas trinta e cinco áreas prioritárias no mundo e desenvolve várias ações visando a conservação e a agropecuária sustentável (WWF, 2015, 2016). 


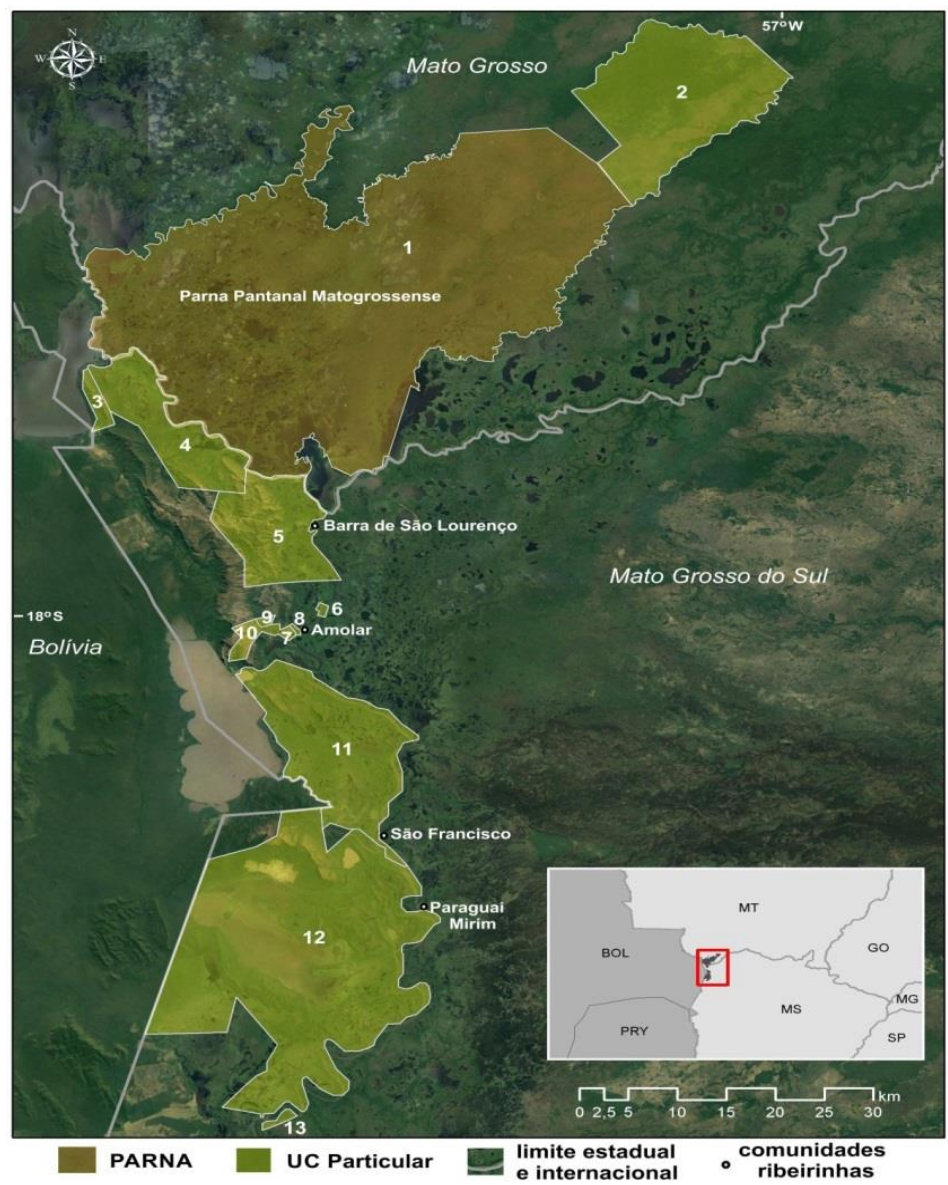

Figura 9 - A rede de unidades de conservação integral do norte do Pantanal. Adaptação de: ICMBio (2016), Bicalho et al. (2020).

Contudo, as ações de preservação ambiental ameaçam os ribeirinhos históricos que há gerações vivem à margem do rio Paraguai, causando um conflito entre duas redes de conservação: 1) a biocêntrica que representa as unidades de conservação públicas e privadas e 2) a socioecológica que atua em favor da população ribeirinha. A rede biocêntrica reúne poderosos grupos empresariais, eco-veranistas e políticos locais que querem reconstituir o Pantanal "natural" sem a presença dos ribeirinhos, estes considerados “agentes antrópicos”. Aproveitando de políticas de compensação ambiental, a declarada preocupação em preservar a natureza do Pantanal oculta a continuidade de degradação ambiental com mineração em Ladário, reservas de valor na Serra do Amolar que possui potencial para mineração, a simples especulação com terras oriundas de fazendas tradicionais falidas, esquemas duvidosos de fundos verdes e até mesmo racismo ambiental. 
A região em que os ribeirinhos vivem atualmente é economicamente deprimida há décadas. As cidades algemadas de Corumbá e Ladário constituem o núcleo urbano mais importante do Pantanal e concentra quase toda a população do município de Corumbá. Em 2010 a população urbana conjunta era de 112.054 habitantes enquanto a zona rural tinha apenas 11.303 habitantes, espalhados em $64.793 \mathrm{~km}^{2}$, com densidade demográfica de 0,2 habitante por $\mathrm{km}^{2}$ (IBGE, 2010). Como acontece no Pantanal inteiro, este quadro provoca êxodo rural de famílias que buscam serviços de educação e de saúde disponíveis em Corumbá (ARAÚJO; BICALHO, 2010). Contudo, há décadas a cidade também está estagnada, uma sombra do seu passado quando escoava o charque do oeste do Brasil para os países latinos, outrora prósperos (BENEVIDES; LEONZO, 2001; SODRÉ, 1941). Hoje só há emprego nos setores de mineração em Ladério e no turismo de pesca esportiva com base em Corumbá.

Um evento climático, nos anos de 1970, deprimiu ainda mais a economia da zona rural perto da Serra do Amolar. A estação chuvosa 1973-1974 foi tão intensa que causou grande erosão, dificultando o escoamento de água rio abaixo e modificando as "flans" fluviais dos tributários, que transformou a pradaria sazonalmente inundada em pântano permanente. A estrada ligando Corumbá com Cuiabá desapareceu, as fazendas tradicionais faliram e os peões perderam seus empregos.

Os ex-trabalhadores se fixaram em Faixa da União ao longo dos rios e se misturaram com os ribeirinhos do rio Paraguai. Estes são descendentes de indígenas, escravos e colonos brasileiros, bolivianos e paraguaios, constituindo um campesinato clássico de região de baixa densidade demográfica. Historicamente havia grande mobilidade espacial rio acima e abaixo, ora se empregando como vaqueiros nas fazendas tradicionais, ora como pescadores-lavradores independentes.

Na pesquisa de campo constatou-se que a população local tem baixo impacto nos recursos naturais. Dos ribeirinhos entrevistados, $73 \%$ não vendem peixe, e só 35\% de toda a pescada é vendida. Se extrapolar dos dados de pesca da amostragem, de uma média de 842 quilos pescados por família por ano, ao universo de 64 famílias ribeirinhas (ECOA, 2014-15), o total de pesca dos ribeirinhos é de 53,888 quilos por ano. A parte vendida visa comprar bens de primeira necessidade, como alimentos e roupa, que não são produzidos localmente, característica clássica de camponeses. Deve ser lembrado que historicamente é raro o camponês que vive da subsistência pura, pois faz parte de uma 
divisão de trabalho mais ampla e enfrenta uma série de obrigações fundiárias e cerimoniais, que requer a produção de uma excedente bem maior do que suas necessidades básicas de alimentação (MENDRAS, 1978; TRIGGER, 2003; WOLF, 1966, 1981).

As atividades agrícolas são mais restritas ainda. Pequenas áreas de por volta de meio hectare de mandioca e milho são plantadas por alguns ribeirinhos em restingas que ficam fora da enchente anual. Porcos e galinhas são criados soltos. Quando estes ficam próximos a áreas alagadas frequentemente são atacados por jacaré, onça e outros predadores. Além disso, alguns ribeirinhos criam uns poucos rés de gado bovino, que junto aos porcos, podem gerar atrito na comunidade quando comem a lavoura do vizinho.

Ribeirinhos também ganham renda vendendo isca viva aos pescadores esportivos, e, eventualmente, aos mesmos, peixe, mel, carvão, galinha e porco. Das famílias entrevistadas, $77 \%$ ganham renda no setor turístico e esta fonte de renda respondeu por $23 \%$ da renda média dos ribeirinhos em 2014. Contudo, a fonte de renda mais importante foi oriunda de repasses sociais na forma de aposentaria e bolsa família, constituindo $46 \%$ da renda total, ou seja, duas vezes a renda gerada pelo setor turístico e três vezes a renda de venda de peixe.

Se o impacto ambiental das atividades dos ribeirinhos é reduzido, o mesmo não é o caso dos pescadores esportivos. Esse setor é responsável pela retirada de mais de um milhão de quilos de peixe de primeira qualidade por ano só no município de Corumbá. Tida como atividade eco-turística, os gestores de unidades de conservação não se preocupam com o impacto dos pescadores esportivos. Contudo, em média, turistas de pesca esportiva capturam 25 quilos de peixe por pessoa (MORAES; SEIDL, 2000) e a Prefeitura de Corumbá estima que mais de 52.000 turistas da pesca esportiva visitam o município por ano (PREFEITURA DE CORUMBÁ, 2015).

Apenas esses dados dão a dimensão do volume pescado por indivíduos em lazer e contrasta com as restrições impostas sobre as populações tradicionais que dependem da pesca para sua sobrevivência. Esta falha de avaliação por parte dos gestores exprime o preconceito de classe e de origem urbana dos agentes públicos frente à população rural pobre. Já os pecadores esportivos são profissionais liberais e comerciantes de classe média e alta que vêm de cidades das regiões Sudeste e Sul (MORAES; SEIDL, 2000). Estes chegam ao Pantanal de carro particular com reboque, trazendo comida, bebida e equipamento de pesca e levam de volta a pescada congelada. O estado do Mato Grosso 
do Sul reconhece este problema, e em 2019 implementou lei autorizando apenas a pesca e soltura no setor esportivo, somente havendo a compra de pescadores locais do peixe levado para casa.

A disputa judicial entre a rede de conservação biocêntrica e a rede socioecológica

O conflito com a população local começou quando os proprietários da margem esquerda do rio Paraguai expulsaram a população ribeirinha que até então residia na área de Faixa da União, em elevações situadas acima da enchente anual, e proibiram a pesca nas RPPNs. Isso fez com que os ribeirinhos se mudassem para a margem oposta, estabelecendo verdadeiros "campos de refugiados da conservação”. Quando os proprietários de imóveis rurais da margem direita também se movimentam para intimidar e expulsar os ribeirinhos daquele lado do rio, cresceu o conflito, resultando na audiência pública de mediação realizada pelo Ministério Público Federal em maio de 2015 .

A audiência contou com a participação de representante do ICMBio e outro da rede de reservas particulares, por um lado, e, por outro lado, a população local, representante de uma ONG ambiental e pesquisadores da UFMS-Corumbá. A audiência foi realizada na pequena comunidade de Barra do São Lourenço, localizada próxima à divisa com Mato Grosso e à zona de amortecimento do Parque Nacional do Pantanal. Em meio a uma das mais remotas áreas do Pantanal montou-se um grande evento de cidadania. Além do Ministério Público, havia a presença de agentes da Polícia Federal em embarcações velozes normalmente usadas no combate ao tráfego de droga e ao contrabando na área de fronteira internacional e da Marinha com um navio de apoio aos agentes do Ministério Público. O porte do aparato e a importância das instituições mobilizadas bem expressam a gravidade do problema local, atraindo ainda membros da imprensa regional e até um jornalista representando a rede de televisão BBC da Inglaterra (veja ERICKSON, 2001, para exemplos de como conflito em pequenos lugares pode assumir significância global).

Foi possível pelas falas dos diferentes atores presentes na audiência pública e tendo-se, anteriormente à audiência, realizado levantamentos de campo junto à população ribeirinha, detectar a raiz do conflito, contrapondo, assim, direitos de populações tradicionais a interesses privados externos resguardados por trás do discurso 
ambientalista e na cooptação de agentes públicos de instituições ambientalistas (Figura $10)$.

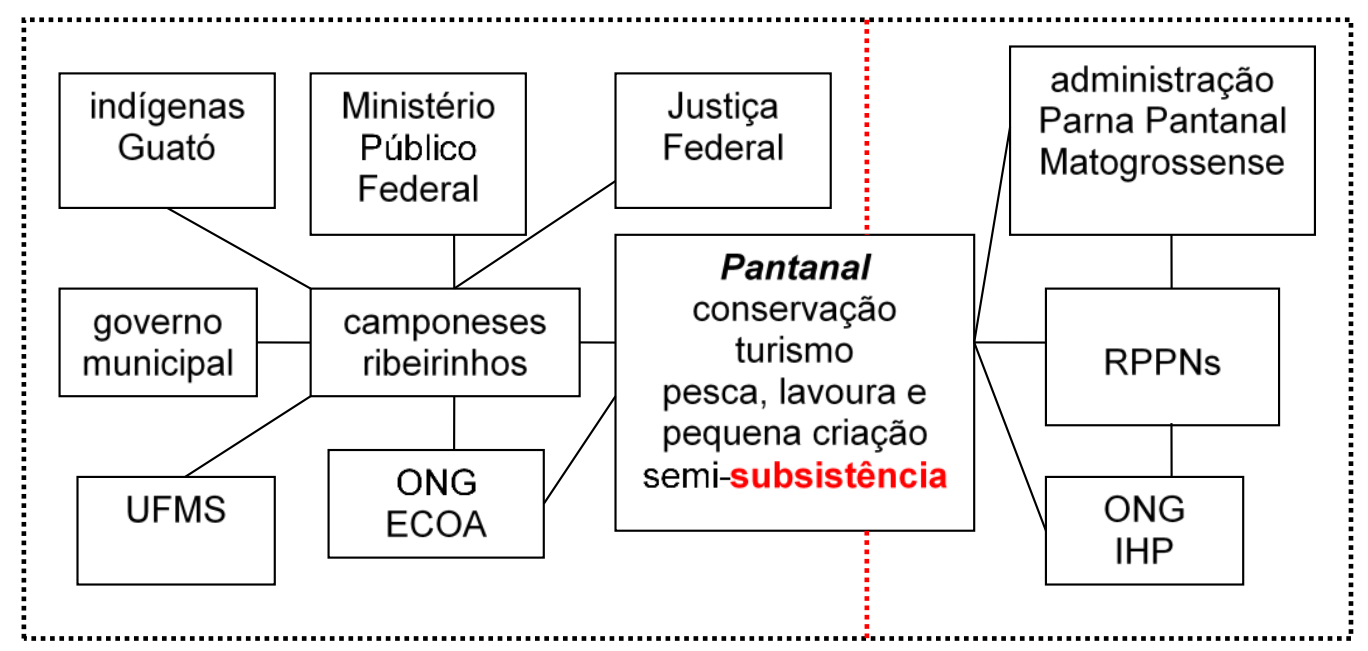

Figura 10 - Redes rivais de conservação socioecológica e de conservação biocêntrica.

As RPPNs foram representadas pelo diretor do Instituto do Homem do Pantanal (IHP), uma organização não governamental com base em Corumbá, que promove a preservação ambiental no Pantanal e sua cultura (IHP, 2016). O diretor é um coronel reformado da polícia militar que nos anos de 1980 liderou a luta contra a caça ilegal de jacaré pelos coureiros (OECO, 2008). Como a Serra do Amolar foi importante entreposto do couro de jacaré, o passado do ex-policial acerba sua ênfase bio-cêntrica e suas ideias elitistas sobre cultura pantaneira que excluem os ribeirinhos. No dia da audiência, ele apareceu vestido de farda de camuflagem de combate na selva para intimidar os ribeirinhos.

O diretor do PARNA do Pantanal na audiência também estava alinhado com as reservas particulares, porque ele considera a população local uma ameaça "antrópica”. A comunidade de Barra do São Lourenço fica logo abaixo do PARNA e os ribeirinhos pescam na zona de amortecimento. O diretor afirmou categoricamente que só ribeirinho que pesca estritamente para sua subsistência podia entrar nessa área, mas não pescador comercial que vende peixe, demonstrando tamanha ignorância sociológica da vida camponesa.

O consórcio de reservas particulares ofereceu reassentar os ribeirinhos sem ônus para um conjunto habitacional construído em Corumbá para eles. As pequenas casas deste tipo de conjunto habitacional são notórias pela baixa qualidade de construção, casas grudadas uma na outra, sem uma única árvore a vista e servidas de ruas sem 
pavimentação que se tornam um lamaçal durante a estação de chuvas. A transferência colocaria os ribeirinhos num bairro periférico de uma cidade com desemprego crônico durante a pior depressão econômica da história do país. Isso repetiria a história norteamericana quando os agricultores pobres das Apalaches foram retirados das novas unidades de preservação integral criadas durante a Grande Depressão da década de 1930 (HOEFLE, 2019).

$\mathrm{Na}$ verdade, $45 \%$ dos ribeirinhos entrevistados já moraram em Corumbá e voltaram alegando não gostar da vida na cidade. Eles até reconheceram que existem melhores serviços de saúde e fornecimento de energia em Corumbá, mas citaram como fatores negativos a falta de emprego para pessoas com baixo nível de instrução, a violência urbana, a presença de drogas e o solidão por falta de amigos.

A Defensoria Pública representava os ribeirinhos. A organização nãogovernamental ECOA também tomou a parte dos ribeirinhos. Esta ONG tem uma história de trabalhar junto aos ribeirinhos promovendo práticas de pesca sustentável e desenvolvimento comunitário. A ECOA foi criada em 1989 por biólogos, arquitetos, cientistas sociais e educadores de Campo Grande e atua na conservação da água urbana e rural (ECOA, 2016). Além disso, professores e estudantes da UFMS-Corumbá estavam presentes na audiência para apoiar os ribeirinhos.

Após horas de preparação a juíza abriu a audiência. Antes de sentar-se à mesa, ela retirou seu sapato, pisou descalço no chão batido mostrando sua solidariedade com a população local e discursou claramente a favor da causa dos ribeirinhos, porque são descendentes de índio, brasileiro, boliviano e paraguaio que sofreram séculos de discriminação. Em seguida, diferentes grupos prestaram testemunha. Os líderes comunitários e o grupo das mulheres falaram sobre sua vida da pesca artesanal ao longo do rio Paraguai. O argumento conclusivo foi fornecido pelo cacique guató e sua esposa que vieram de sua terra indígena localizada rio acima. Estes afirmaram que os ribeirinhos têm ascendência guató e, como eles, têm direitos tradicionais de permanência.

A audiência pública teve como resultados posteriores a concessão do direito de uso da Terra da União para as moradias dos ribeirinhos, do direito de ficar em algumas áreas elevadas dentro das unidades de conservação na época do cheio e do direito de pescar em certas áreas do PARNA localizadas ao longo do rio Paraguai e seus tributários (veja BICALHO et al., 2020 para maiores detalhes).

Assim sendo, o caso dos ribeirinhos do rio Paraguai envolveu cooperação entre segmentos da população local e não atrito como vimos acima no caso tratado na 
Amazônia. A cooperação guató não se limita à ajuda no movimento de permanência no lugar, mas também estende ao ensino de artesanato pela mulher do cacique que exerce grande liderança entre as mulheres ribeirinhas. A extensa rede de parceiros extralocais também foi de grande importância para o sucesso do movimento de permanência.

\section{Debatendo a conservação socioecológica e a identidade híbrida}

Num momento de retorno ao velho desenvolvimento predatório no país e negacionismo ambiental em outros países, a conservação socioecológica surge como estratégia de meio termo entre a ética ambiental biocêntrica, que só leva em conta o bem do ecossistema, e a antropocêntrica, que só se importa com o bem humano. Neste ponto, as três abordagens teóricas usadas no trabalho estão de acordo. Ao contrário do modelo norte-americano de conservação integral, as políticas de conservação socioecológica são consagradas no planejamento regional da União Europeia. É importante ressaltar que os dois tipos de conservação existem no país desde 2000, quando foi promulgado o Sistema Nacional de Unidades de Conservação (SNUC), que abriu a possibilidade do uso sustentável por populações tradicionais em Floresta Nacional, Reserva Extrativista e Reserva de Desenvolvimento Sustentável.

Contudo, o desenvolvimento sustentável não pode ser entendido como a mera produção de "subsistência" por parte da "população tradicional". Estes dois conceitos são extremamente polêmicos nas ciências humanas de forma que parte da formação de qualquer biólogo ou engenheiro ambiental requer treinamento nestas disciplinas e idealmente na abordagem relacional. Com base em modelos socioecológicos, o futuro gestor de unidade de conservação entenderia melhor que o desenvolvimento sustentável significa elaborar novos sistemas produtivos e atividades agrícolas e não agrícolas que promovem a conservação ambiental, a inclusão social e uma vida digna para populações locais atingidas por novas unidades de conservação. A experiência da FLONA Tapajós tratada aqui ensina que é justamente a população local que tem melhor noção de quais atividades são viáveis ou não, de forma que esta deve ser parceiro chave em qualquer aplicação concreta de políticas gerais de conservação.

Já os territórios étnicos no país geram muito mais polêmica. Há consenso que o Brasil é um dos países mais desiguais do planeta. Em 2015 o índice GINI Era 0,513, as famílias mais ricas detinham $40,4 \%$ da riqueza nacional e as $10 \%$ mais pobres, apenas 1,2 \% (WORLD BANK, 2018). Para mudar este quadro, no início do século XXI, novas 
políticas étnicas foram implementadas junto a outras políticas visando reduzir a pobreza e a fome. Apesar de serem bem intencionadas, porém, as novas políticas étnicas utilizam critérios de "raça" para definir acesso aos territórios segregados para dois grupos étnicos historicamente discriminados, "indígenas" e "negros", categorias essas colocadas em oposição aos "brancos".

No campo intelectual, as políticas vão contra teorias atuais da identidade híbrida que ressaltam a combinação de elementos de identidades diferentes por uma mesma pessoa em determinados momentos de sua vida cotidiana, e até mesclados simultaneamente. Jamieson (2003) apresenta um estudo de caso mostrando como os ameríndios miskitus da Nicarágua, ora se consideram "miskitu", ora "creole” (o equivalente de "caboclo" na Amazônia), podendo até misturar elementos num mesmo contexto, como, por exemplo, em festividades. Isso é tão antigo quanto a colonização europeia nas Américas e mesmo entre populações ameríndias que vivem em localidades remotas e ainda mantêm um modo de vida tribal.

Considere a fotografia de um ie'quana vestido para uma festividade em 1975, em uma aldeia situada nas cabeceiras do Rio Branco (Figura 11). O homem veste miçanga e pano vermelho, ambos manufaturados, e um cocar indígena colocado acima de um gorro também manufaturado que tem listas de cor vermelha. Tal cor tem grande significado simbólico entre populações nativas das Américas, e objetos pessoais com essa cor são altamente valorizados (LÉVI-STRAUSS, 1969). Para obter os objetos de fora os ie'quanas viajam rio abaixo e trabalham uma temporada construindo canoas ou se empregando como trabalhadores. Contudo, de volta à aldeia, os objetos são ressignificados dentro de um contexto tribal, incluindo em festividades que ainda podem ser encontradas hoje em dia (ART-AMAZON, 2020). 


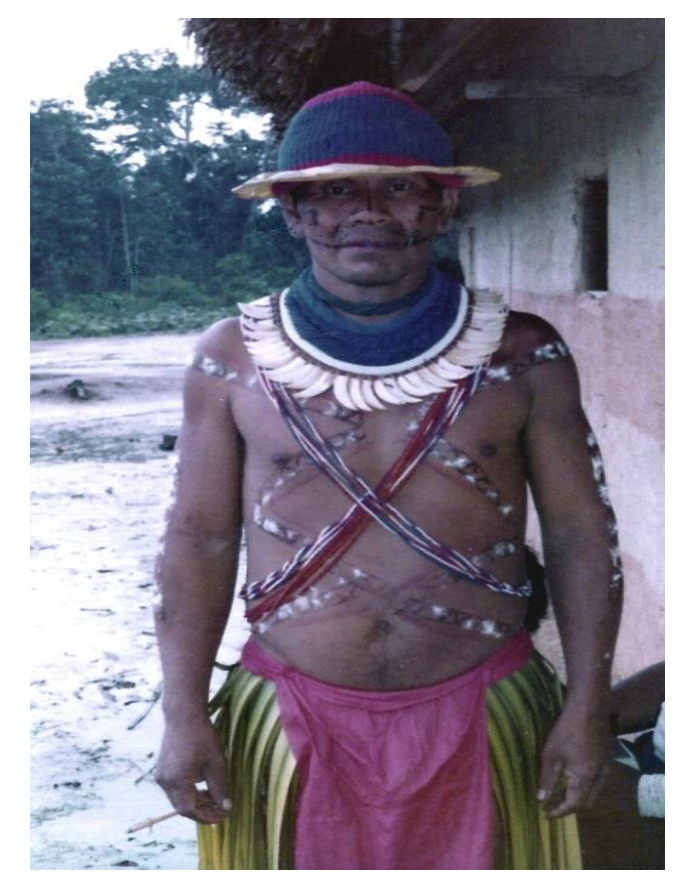

Figura 11 - Ie’quana mistura vestimenta indígena e não indígena em momento de festa. Fonte: Pesquisa de campo (1975).

As políticas étnicas brasileiras também ignoram novas tendências de recenseamento no mundo que realçam a complexidade de origens sociais e procuram evitar o conceito desacreditado de "raça". No lugar deste, utiliza-se o conceito de "etnicidade" com base em definições culturais que inclusive permitem o respondente de enquête de recenseamento declarar uma mistura de origens. Além disso, idealmente, o processo de definir o grupo social de indivíduos levantados pelo censo deveria envolver uma dialética interno-externa de identificação, que combina a identificação por grupo (como os membros se autodenominam) e a categorização social (como são definidos por observadores externos ao grupo) (ASPINALL, 2009). Esta solução parece atender às críticas que Latour (2013) faz à “identidade”.

Também existem enormes problemas em como definir identidade, particularmente numa região como a Amazônia. Em revisão bibliográfica sobre saúde indígena, Valeggia e Snodgrass (2015) apontam duas maneiras de definir grupo étnico: 1) antropólogos biológicos utilizam basicamente marcadores genéticos em comum para identificar indígenas e 2) antropólogos sociais e sociólogos definem etnicidade por critérios de status político e de reconhecimento de parentesco biológico e cultural em comum, constituído em relações mútuas de longa data situadas em paisagens vividas específicas.

Os dois modos de identificar etnicidade podem gerar resultados bem diferentes e até mesmo contestáveis. Santos et al. (2009) em estudo sobre a percepção de raça versus a análise genética de alunos do IFCS-UFRJ reportam que a percepção social dos alunos ESPAÇO E CULTURA, UERJ, RJ, JAN./JUN. DE 2021, N. 49, P. 44-84 http://www.e-publicacoes.uerj.br/index.php/espacoecultura/ 
era de um alto teor ancestral africano e médio teor indígena enquanto a análise genômica revelou alto teor europeu, baixo a médio teor africano e nenhum teor indígena. Reforçando os problemas de reconhecimento de etnicidade, Blanchard et al. (2019) explicam que indígenas norte-americanos resistem ao uso de Testes de Ascendência Genética para definir identidade porque os testes usurpam suas práticas legais, sociais e políticas utilizadas historicamente para construir sua identidade. Também, os indígenas são altamente céticos à Ciência Ocidental que no passado imperialista prestou serviço em expulsão territorial, genocídio, eugenia, assimilação forçada e desautorização do conhecimento indígena.

Até a identidade por territorialidade é problemática. Em dois trabalhos separados, Alexiades e Peluso (2015) e McSweeney e Jokisch (2007) questionam o critério da paisagem cultural compartilhada por longa data, pois hoje a grande maioria dos indígenas da América do Sul vive em cidades e não mais nos territórios étnicos. Podemos então perguntar: Nas cidades são "indígenas”, membros de mais um grupo étnico e nos territórios remotos são "ameríndios”, povos tribais? E quando há movimento pendular entre a cidade e a aldeia, ou quando a aldeia se localiza na periferia urbana e os indígenas engajam regularmente em trabalho assalariado rural e urbano?

A adoção do conceito de "ação afirmativa" no Brasil também é problemática por razões políticas devido a sua origem norte-americana. No contexto da Guerra Fria e da caça a "comunistas subversivos" nos Estados Unidos durante a infância do autor era politicamente tabu tratar desigualdade em termos de classe social. Sendo assim, era necessário buscar outras formas de identificar grupos de baixa renda, sendo cor fortemente associada à pobreza. Com o tempo foram incluídos outros critérios de discriminação a serem combatidos com ação afirmativa como, por exemplo, gênero, zona de residência, região de origem, etc. Até hoje qualquer tentativa de abordar a crescente desigualdade nos Estados Unidos é rebatida por políticos conservadores contrários à "guerra de classe", e reformistas são pichados de serem "socialistas", atualizando a velha acusação de serem "comunistas”. O resultado é uma visão da sociedade fragmentada por critérios horizontais e verticais de identidade que dificultam a mobilização política para contestar a elevada concentração da riqueza não somente nos Estados Unidos, mas em nível global.

Contra esta visão fragmentada da sociedade norte-americana existe uma literatura histórica sobre como o racismo reforça a desigualdade econômica nos guetos urbanos dos Estados Unidos. Em número temático da Professional Geographer sobre 
estudos da "economia racial", Wilson atualiza e torna mais robusta esta perspectiva, mesclando a economia política marxista, que foca como descriminação racial agrava segregação residencial e pobreza, com abordagens pós-modernistas e pósestruturalistas, acrescentando novos elementos culturais dos estudos sobre "branquitude", pós-colonialismo, construção social, espacialidade, governança e regulamentação neo-liberal (2009, 140-141).

Assim sendo, não deve ser perdido de vista o problema da desigualdade por classe quando se tratam questões de diferença e diversidade. Avaliações recentes oferecem críticas contundentes às políticas de diversidade quando isoladas de reformas mais radicais. Pan (2020, 62-63) cita a obra pioneira The Trouble with Diversity, na qual Michaels afirma que "na melhor hipótese as políticas de diversidade representam uma distração e na pior hipótese são reacionárias” para questionar se seria socialmente mais aceitável o fato que o grupo dos 1\% mais ricos dos Estados Unidos detém 50\% riqueza da nação, se o grupo era composto por 50\% mulher, $14 \%$ negro, $18 \%$ latino e $3 \%$ asiático, correspondendo, assim, à proporção de cada grupo na população geral. O renomado cientista político afro-americano Adolf Reed Jr. publicou uma série de artigos sobre o tema classe importa, na qual argumenta que historicamente pessoas de cor nos Estados Unidos foram mais beneficiadas por políticas universais de redistribuição de renda e de providência social do que por políticas de diversidade que têm como alvo grupos específicos (2019a, 2019b, 2020).

Finalmente, por questões políticas, Frake (2014) considera o conceito de “indígena" muito problemático, pois envolve a validação do status de uma pessoa como membro de um grupo social utilizando uma categoria coletiva simplista atribuída por organizações governamentais e não governamentais externas. Baseada na sua longa experiência de pesquisa nas Filipinas, Frake mostra como o conceito de "indígena” substituiu outras categorias anteriores que tinham o sentido negativo de povos isolados, atrasados e marginais. Naquele país, categorias como "tribo" e "tradicional" foram impostas historicamente por grupos dominantes visando regimentar e oprimir populações locais que eram muito diferentes entre si. Assim sendo, o termo indígena representa apenas uma mudança de rótulo. Como no passado, o termo indígena é usado para pessoas que vivem numa sociedade com economia autossuficiente e sistema político com "chefe" que mobiliza a população em prol do bem comunitário.

Frake contrasta a caricatura do indígena com a história complexa das Filipinas, marcada por sucessivas transformações culturais mesmo antes do advento do 
colonialismo capitalista europeu. Com base nesta história, Frake questiona se as vantagens materiais oferecidas pelas organizações governamentais e ONGs compensam o estigma de assumir uma identidade inventada que pode marginalizar a população ainda mais em comparação ao resto da sociedade. O conceito de "indígena”, portanto, é um "saco de gato" que junta segmentos sociais diferentes com pouca afinidade para tentar construir movimentos políticos em comum, um empreendimento que Frake considera fadado a fracasso. Assim sendo, como neste trabalho, Frake, através da pesquisa etnográfica histórica, chega à mesma conclusão de Latour (2013), quando este critica visões essencialistas da identidade e no seu lugar propõe uma visão relacional-híbrida.

Agradecimentos

Apoio do CNPq e da FAPERJ.

\section{REFERÊNCIAS BIBLIOGRÁFICAS}

ADAMS, W. M., MULliGAN, M. (orgs.). Decolonizing nature: strategies for conservation in a post-colonial era. London: Earthscan, 2003.

ALEXIADES, M. N.; PELUSO, D. M. Introduction: indigenous urbanization in lowland South America. The Journal of Latin American and Caribbean Anthropology. Vol. 20, n. 1, p. 1-12, 2015.

ART-AMAZON. Ye'kuana baskets, 2020. https://www.arte-amazonia.com/ shop/amazon-baskets/ye-kuana-baskets, acesso 24/24/2020.

BENEVIDES, C.; LEONZO, N. Miranda Estância. Rio de Janeiro: Fundação Getúlio Vargas, 2001.

ARAUJO, A. P.; BICALHO, A. M. S. M. O rural em movimento: a pecuária nas transformações espaciais do Pantanal. Campo Grande: UFMS, 2010.

ASPINALL, P. J. Mixed race, mixed origins or what? Anthropology Today. Vol. 25, n. 2, p. 3-8, 2009.

BICALHO, A. M. Capital social na várzea amazônica. In: BICALHO, A. M., GOMES, P. C. C. (Orgs.) Questões metodológicas e novas temáticas na pesquisa geográfica. Rio de Janeiro: Publit, 2009, p. 93-122.

Reestruturação rural e participação política no entorno de Manaus. In: ARAUjO, R., LÉNA, P. (Orgs.) Desenvolvimento sustentável e sociedades na Amazônia. Belém: Museu Goeldi, 2010, p. 409-446.

BICALHO, A. M. S. M.; HOEFLE, S. On the cutting edge of the Brazilian frontier. Journal of Peasant Studies. Vol. 35, n. 1, p. 1-38, 2008. 
Economic development, social identity and community empowerment in the central and western Amazon, Geographical Research. Vol. 48, n. 3, p. 281-296, 2010.

Conservation units, environmental services and frontier peasants in the Central Amazon. In: WOOD, D.C. (Org.), Climate Change, Culture, and Economics. Bradford: Emerald Scientific, 2015, p. 67-105.

BICALHO, A. M. S. M.; HOEFLE, S. W.; ARAUJO, A. P. Ribeirinhos em resistência à gestão biocêntrica de unidades de conservação pública e privada no Pantanal. Espaço Aberto. Vol. 10, n. 2, p. 206-235, 2020.

BLANCHARD et al. We don't need a swab in our mouth to prove who we are. Current Anthropology. Vol. 60, n. 5, p. 637-655, 2019.

BORRAS JR., S. M., HALL, R., SCOONES, I., WHITE, B., WOLFORD, W. Towards a better understanding of global land grabbing. Journal of Peasant Studies. Vol. 38, n. 2, p. 209-216, 2011.

BUMPUS, A. G.; LIVERMAN, D. M. Carbon colonialism? In: PEET, R.; ROBBINS, P.; MATTS, J. (Orgs.), Global Political Ecology. Milton Park: Routledge, 2011, p. 203224.

BÜSCHER, B., FLETCHER, R. Accumulation by conservation. New Political Economy. Vol. 20, n. 2, p. 273-298, 2014.

Under pressure: conceptualising political ecologies of green wars. Conservation and Society. Vol. 16, n. 2, p. 105-113, 2018.

CHARNELY, S., POE, M. Community forestry in theory and practice. Annual Review of Anthropology. Vol. 36, p. 301-336, 2007.

CHIBNIK, M. Risky rivers. Tuscon, University of Arizona Press, 1994.

COIAB (Coordenação das Organizações Indígenas da Amazônia Brasileira). Informativo da COIAB. n. 2-10, 1991-1998.

Quem somos, 2020. https://coiab.org.br/quemsomos. acesso 10/11/2020.

COLCHESTER, M. Beyond tenure. Washington: Rights and Resources Initiative, 2008.

COSTA, S. M. G., VIEIRA, J. C., LIMA, M. V. C. L., MILEO, B. P. Territorialização e identidade indígena no baixo Tapajós no Estado do Pará. In: IV Jornada Internacional de Políticas Públicas. São Luiz, UFMA, 2013, p. 1-10.

CRESSWELL, T. Geographical thought. Chichester: Blackwell-Wiley, 2013.

CRONIN, W. Nature's Metropolis. New York: Norton, 1991.

DESCOLA, Ph. Beyond nature and culture. Chicago: Univ. Chicago Press, 2013.

DOWIE, M. Conservation refugees. Cambridge, MIT Press, 2009. 
ECOA (Ecologia e Ação). Comunidades tradicionais: Paraguai Mirim e São Francisco, 2014a. Disponível em: http://riosvivos.org.br/comunidades /comunidadestradicionais-comunidades/paraguai-mirim-e-sao-francisco, acesso: 25/02/2016.

Comunidades tradicionais: Barra de São Lourenço, 2014b. http://riosvivos.org.br/comunidades/comunidades-tradicionais-comunidades/barrado-sao-lourenco, acesso: 25/02/2016.

_. Comunidades tradicionais: Serra do Amolar, 2015. http://riosvivos.org.br/comunidades/comunidades-tradicionais-comunidades/ serrado-amolar, acesso: 25/02/2016. 25/02/2016.

Quem somos, 2016. http://riosvivos.org.br/institucional-2/ecoa, acesso

EDELMAN, M. Social movement. Annual Review of Anthropology. Vol. 30, p. 285-371, 2001.

ERICKSON, T. Little places, large issues. London: Pluto Press, 2001.

FORSYTH, T. Critical political ecology: the politics of environmental science. Milton Park: Routledge, 2003.

FIELDING, A. J. Counterurbanisation. In: Pinder, A. (Org.) Western Europe. London: Wiley, 2000, p. 226-239.

FRAKE, C. O. How to be a tribe in the southern Philippines during the advent of NGOs and the invention of the indigenous. Human Organization. Vol. 73, n. 3, p. 197-204, 2014.

FUNAI (Fundação Nacional do Índio). Terra indígenas. http://www.funai.gov.br/ index.php/indios-no-brasil/terras-indigenas, acesso 14/10/2018.

GRIfFIN, C.; JONES, R.; ROBERTSON, I. (Orgs.), Moral Ecologies. Cham: Palgrave Macmillan Spinger, 2019.

HARRIS, M. What it means to be caboclo. Critique of Anthropology. Vol. 18, p. 83-95, 1998.

HARRISON, S. Cultural boundaries. Anthropology Today. Vol. 15, n. 5, p. 10-13, 1999.

HIRAOKA, M. Caboclo and ribereño resource management in Amazonia. In: REDFORD, K. H., PADOCH, C. (Orgs.) Conservation of neotropical forests. New York: Columbia Univ. Press, 1992, p. 134-157.

HOBSBAWN, E. Industry and empire. London: Penguin, 1969.

HOEFLE, S. W. Patronage and empowerment in the central Amazon. Bulletin of Latin American Studies. Vol. 19, n. 4, p. 479-499, 2000.

Eliminating scale and killing the goose that laid the golden egg? Transactions of the Institute of British Geographers. Vol. 31, n. 2, p. 238-243, $2006 \mathrm{a}$.

Twisting the knife. Journal of Peasant Studies. Vol. 33, n. 3, p. 445-478, 2006 b. 
2013.

Colonialismo carbônico na Amazônia? Espaço Aberto . Vol. 3, n. 2, p. 109-130,

A fronteira agrícola na Amazônia no século XXI. Revista Brasileira de Geografia. Vol. 61, n. 1, p. 13-50, 2017.

Ghosts in the forest. In, GRIFFON, C.; JONES, R.; ROBERTSON, I. (Orgs.), Moral Ecologies. Cham: Palgrave Macmillan Spinger, 2019, p. 99-125.

The uncertain future of conservation and identity politics in the Amazon. In, DANIELS, J. (Org.), Advances in Environmental Research 70. New York: Nova Science, 2020, p. 55-102.

HOlBRAAD, M.; PEDERSEN, M. A. The ontological turn. Cambridge: Cambridge Univ. Press, 2017.

IBAMA (Instituto Brasileiro do Meio Ambiente e dos Recursos Naturais Renováveis). Plano de manejo: Floresta Nacional do Tapajós. Brasília, 2005.

IBGE (Instituto Brasileiro de Geografia e Estatística). Aveiro, Pará, histórico. https//cidades.ibge.gov.br/brasil/pa/aveiro/historico, acesso 09/09/2016.

Corumbá, Ladário. https://cidades.ibge.gov.br/brasil/ms/corumba/panorama, acesso 07/11/2020.

ICMBio (Instituto Chico Mendes de Conservação da Biodiversidade). Floresta Nacional do Tapajós, 2014. www.icmbio.gov.br/flonatapajos, acesso 13/10/2014.

IHP (Instituto Homem Pantaneiro). Histórico, 2016. www.institutohomem pantaneiro.org.br/?conteudo=canal\&canal_id=9., acesso 04/05/2016.

ISA (Instituto Socioambiental). Terra indígena Bragança/Marituba e Terra indígena Munduruku-Taquara. http://ti.socioambiental.org/pt-br/\#!/pt-br/terrasindigenas/4178/4176, acesso, 14/10/2014.

JACOBY, K. Crimes against nature. Berkeley: University of California Press, 2014.

JAMIESON, M. Meskitu or creole? Ethnic identity and the moral economy in a Nicaraguan Miskitu village. Journal of the Royal Anthropological Institute. Vol. 9, n. 2, p. 201-222, 2003.

Jones III, J.P., K. Woodward, and S. Marston. Situating Flatness. Transactions of the Institute of British Geographers. Vol. 32, n. 2, p. 264-276, 2007.

KELLY-REIF, K.; WING, S. (2016). Urban-rural exploitation. Journal of Rural Studies. Vol. 47, p. 350-358.

LARSON, A. M., BARRY, D., DAHAL, G. R. Tenure change in the global South. In: LARSON, A. M., BARRY, D., DAHAL, G. R., COLFER, C. J. P. (Orgs.) Forests for people. London: Earthscan, 2010, p. 3-18.

LATOUR, B. We have never been modern. New York: Harvester, 1993.

Politics of nature. Cambridge, MS: Harvard Univ. Press, 2004. 
Reassemblying the social. Oxford: Oxford Univ. Press, 2005.

A disputatio: nature versus culture. Anthropology Today. Vol. 25, n. 2, p. 1-2, 2009.

An inquiry into modes of existence. Cambridge: Harvard Univ. Press, 2013.

LAVE, R. 2015. Reassembling the structural. In: PERREAULT, T.; BRIDGE, G.; McCARTHY, J. (Orgs.), The Routledge Handbook of Political Ecology. New York: Routledge, p. 213-223.

LIETNER, H.; MILLER, B. Scale and the limitations of ontological debate. Transactions of the Institute of British Geographers. Vol. 32, n. 1, p. 116-125, 2007.

LÉVI-STRAUSS, C. The raw and the cooked. Chicago: Univ. of Chicago Press, 1969.

McSWEENEY, K.; JOKISCH, B. 2007. Beyond rainforests: urbanisation and emigration among lowland indigenous societies in Latin America". Bulletin of Latin American Research. Vol. 26, p. 159-180.

MARSTON, S.A.; JONES III, J.P.; WOODWARD, K. Human geography without scale. Transactions of the Institute of British Geographers. Vol. 30, n. 4, p. 416-432, 2005.

MENDRAS, H. Sociedades camponesas. Rio de Janeiro: Zahar, 1978.

MMA/ICMBio (Instituto Chico Mendes de Conservaçao da Biodiversidade). Patrimônio natural da humanidade, Pantanal guarda biodiversidade única, 2010. https://www.mma.gov.br/ informma/item/6622-patrimonio-natural-da-humanidadepantanal-guarda-biodiversidade-unica, acesso 26/2/2016.

MOLNAR, A. Forest tenure reform in Indonesia. Anthropology News. Vol. 52, n. 9, p. 18, 2011.

MORAES, A.; SEIDL, A. Perfil dos pescadores esportivos do sul do Pantanal. Corumbá: EMBRAPA, 2000.

MURDOCH, J. Networking rurality. In: CLOKE, P.; MARSDEN, T.; MOONEY, P. (Orgs.) Handbook of rural studies. London: Sage, 2006, p. 171-184.

NEUMANN, R. F. The political ecology of scale. In: BRYANT, R. L. (Org.), The international handbook of political ecology. Cheltonham: Edward Elgar, 2015, p. 475-486.

NUGENT, S. Amazonian caboclo society. Oxford: Berg, 1993.

2002.

Whither o campesinato?. Journal of Peasant Studies. Vol. 29, n. 2, p. 162-189,

Indigenism and cultural authenticity in Brazilian Amazonia. Goldsmith Anthropology Research Papers n. 15, p. 1-18, 2009.

PADOCH, C., AYRES, J. M., PINEDO-VASQUEZ, M., HENDERSON, A. (Orgs.). Várzea. New York: New York Botanical Gardens Press, 1999.

PAGE, B.; PEET, R. (1994). Nature's metropolis: the ghost dance of Christaller and von Thunen. Antipode. Vol. 26, n. 2, p. 152-162, 1994. 
PAN, J. C. Minding the gap. The New Republic. n. January/February, p. 60-63, 2020.

PARKER, E. P. The Amazon caboclo. Williamsburg: College of William and Mary, 1985.

PEET, R., ROBBINS, P., WATTS, M. Global nature. In, PEET, R., ROBBINS, P., WATTS, M. (Orgs.), Global political ecology. Milton Park: Routledge, 2011 , p. 1-52.

PEIXOTO, R. C., ARENZ, K., FIGUEIREDO, K. O movimento indígena no baixo Tapajós. Novos Cadernos NAEA. Vol. 15, n. 2, p. 279-313, 2012.

PINTO, V. P. S. A implantação da reserva de desenvolvimento sustentável Mamirauá. Dissertação (Mestrado em Geografia), Instituto de Geociências, Universidade Federal do Rio de Janeiro, Rio de Janeiro, 1997.

- Alternativas de desenvolvimento sustentável na Amazônia Brasileira: a gestão cabocla nas várzeas de Silves, AM. Rio de Janeiro, 2004. Tese (Doutorado em Geografia), Instituto de Geociências, Universidade Federal do Rio de Janeiro.

PREFEITURA MUNICIPAL DE CORUMBÁ. Balanço da temporada de pesca esportiva mostra crescimento no turismo corumbaense, InformeMS, p. 1-3, 2015. http://informems.com/Posts/view/2059\#!, acesso 04/04/2016.

RAFFESTIN, C. Por uma geografia do poder. São Paulo: Ática, 1993.

REED JR., A. 2019a. Reduced and Abandoned: On the myth of class reductionism. The New Republic. Vol. October, p. 10-11, 2019a.

----. 2019b. The despair of the disparitians: universalist programs are not intrinsically racist. The New Republic. Vol. December, p. 10-11, 2019 b.

----. 2020. Bookerism and the black elite: managing race relations from above. The New Republic. Vol. February, 2020. https://newrepublic.com/article/ 156419/bookerismblack-elite, acesso 02/24/2020.

RODSETH, L. Back to Boas, forth to Latour. Current Anthropology. Vol. 56, n. 6, p. 865$882,2015$.

RRI (Rights and Resources Initiative). Accelerating reforms in forest rights, governance and markets, 2011. https://rightsandresources.org/wp-content/exported-pdf/ rrgstateofplayfinal22nov 11.pdf, acesso 10/09/2012.

SANTOS, R.V., FRY, P. H.; MONTEIRO, S.; MAIO, M. C.; RODRIGUES, J. C.; BASTOS-RODRIGUES, L.; PENA, S. D. J. 2009. Color, race, and genomic ancestry in Brazil. Current Anthropology. Vol. 50, n. 6, p. 787-819, 2009.

SCOONES, I., HALL, R., BORRAS JR., S. M., WHITE, B., WOLFORD, W. Towards a better understanding of global land grabbing. Journal of Peasant Studies. Vol. 40, n. 3, p. 469-483, 2013.

SISKIND, J. To hunt in the morning. Oxford: Oxford Univ. Press, 1973.

SODRÉ, N. Oeste. Rio de Janeiro: José Olympio, 1941. 
SÖKEFELD, M. Debating self, identity and culture in Anthropology. Current Anthropology. Vol. 40, n. 4, p. 417-447, 1999.

TRIGGER, B. Understanding early civilizations. Cambridge: Cambridge Univ. Press, 2003.

VALEGGIA, C. R.; SNODGRASS, J. J. Health of indigenous peoples. Annual Review of Anthropology. Vol. 44, p. 117-135, 2015.

VAZ FILHO, F. A. A emergência étnica de povos indígenas no baixo Rio Tapajós, Amazônia. Tese (Doutorado em Antropologia Social), Faculdade de Filosofia e Ciências Humanas, Universidade Federal da Bahia, Salvador, 2010.

Povos indígenas no baixo Tapajós querem reconhecimento. In: RICARDO, C. A.; RICARDO, F. (Orgs.) Povos indígenas do Brasil 2006/2010. São Paulo: ISA, 2011, p. 423-426.

VIVEIROS DE CASTRO, E. Cosmological deixis and Amerindian perspectivism. Journal of the Royal Anthropological Institute. Vol. 4, n. 3, p. 469-88, 1998.

WHATMORE, S. Hybrid geographies. London: Sage, 2003.

WILSON, D. Racialized poverty in U.S. Cities: toward a refined racial economy perspective. Profession Geographer. Vol. 61, n. 2, p. 139-149, 2009.

WORLD BANK. Gini index: Brazil, Income share held by highest 10\%, Income share held by lowest 10\%. Disponível em https://data.worldbank.org/ indicator/=BR, acesso $11 / 12 / 2018$.

WOLF, E. R. Peasants. Englewood Cliffs: Prentice Hall, 1966.

Europe and the people without history. Berkeley, Univ. California Press, 1982.

WOODS, M. Rural. Milton Park: Routledge, 2011.

WWF (World Wildlife Fund). Áreas prioritárias para conservação da biodiversi-dade no cerrado e pantanal, 2016. http://www.wwf.org.br/natureza_ brasileira/reducao_de_impactos2/ lep/ lep_pub/?50162/reas-Prioritrias-paraconservao-da-biodiversidade-no-Cerrado-e-Pantanal, acesso 06/06/2016. 